\title{
Crystalline Inclusion of Wheel-and-Axle Diol Hosts Featuring Benzo[b]thiophene Units as a Lateral Construction Element
}

Felix Katzsch, Tobias Gruber* and Edwin Weber*

Institut für Organische Chemie, Technische Universität Bergakademie Freiberg, Leipziger Strasse 29, D-09596 Freiberg/Sachsen, Germany 


\section{ABSTRACT}

By applying the 'wheel-and-axle' host concept and incorporating a previously developed heteroaromatic substitution strategy, a new type of diol hosts featuring two di(benzo[b]thien-2-yl)hydroxymethyl units attached to both ends of a central ethynylene (3) and 1,4-phenylene (4) moiety is reported. The syntheses of the host compounds are described and solvent inclusion formation via crystallization has extensively been studied showing a remarkable inclusion capability of the compounds. X-ray diffraction analysis of relevant crystal structures have been performed and comparatively discussed. Vapor sorption behavior of the compounds as solid receptor films coated on a quartz crystal microbalance considering a variety of solvent vapors has been scrutinized, indicating potential application as mass sensitive materials. 


\section{INTRODUCTION}

With reference to aspects of crystal engineering ${ }^{1-3}$ aiming at applications such as compound separation and storage, ${ }^{4-7}$ crystalline hosts derived from coordinato-clathrate ${ }^{8,9}$ and wheel-and-axle ${ }^{10,11}$ strategies are a major success. In a prototype structure, they feature two bulky diarylhydroxymethyl moieties attached to a central linear building element. A variety of structures corresponding to this general line of molecular design have been performed. ${ }^{12}$ They involve varied expansions of the central rigid axis ${ }^{13,14}$ or increase of the terminal groups including additional substituents. ${ }^{15,16}$ Only recently, a further structural variation viz. the replacement of the terminal aryl moieties by heteroaromatic units has been carried out. ${ }^{17}$ Thereby, substitutions of phenyl groups in the parent structure $\mathbf{1}^{18,19}$ against 2-pyridyl or 2thienyl residues (Fig. 1) have been executed. As a result, in the case of the 2-pyridyl analogue, a distinct decline of the property to include organic guest molecules in the crystalline state is observed, ascribed to a decreased affinity of the hydroxyl groups to guests by reason of intermolecular $\mathrm{O}-\mathrm{H} \cdots \mathrm{N}$ hydrogen bonding. On the other side, the situation is a different one for the 2-thienyl derivative 2 (Fig. 1) lacking of a similar intramolecular interaction that prevent guest binding and, thus, showing a more pronounced inclusion of organic guests. Host $\mathbf{2}$ is not as versatile in its inclusion behavior as $\mathbf{1}$, though features an improved selectivity in inclusion formation. ${ }^{17}$ In order to elaborate this characteristic, we intended to increase the steric demand of the terminal groups while retaining the thiophene building element. This has given rise to the design of the potential host compounds 3 and 4 (Fig. 1) featuring the more bulky benzo[b]thiophen-2-yl moiety instead of simple thiophen-2-yl. 
<smiles>OC(c1ccccc1)(c1ccccc1)c1ccc(C(O)(c2ccccc2)c2ccccc2)cc1</smiles>

1

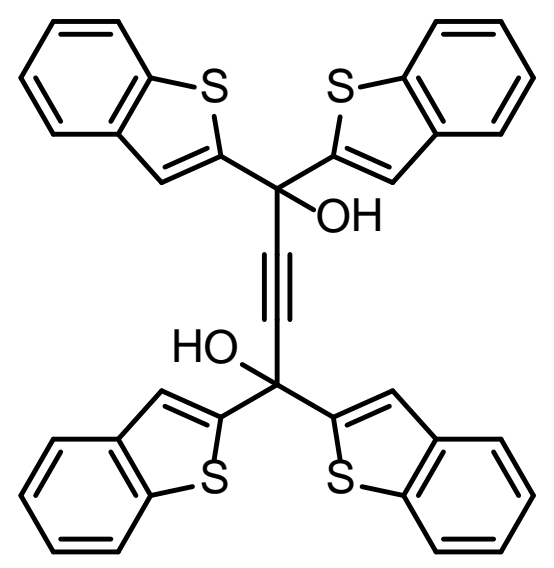

3

3a: 3 ' $n$-butanol (1:2)

3b: 3 ' pyrrolidine (1:2)

3c: 3 - acetone (1:2)

3d: $3 \cdot$ DMSO (1:2)

3e: $3 \cdot$ DMF (1:2)

3f: 3 ' THF (1:2)<smiles>OC(c1ccc(C(O)(c2cccs2)c2cccs2)cc1)(c1cccs1)c1cccs1</smiles>

2

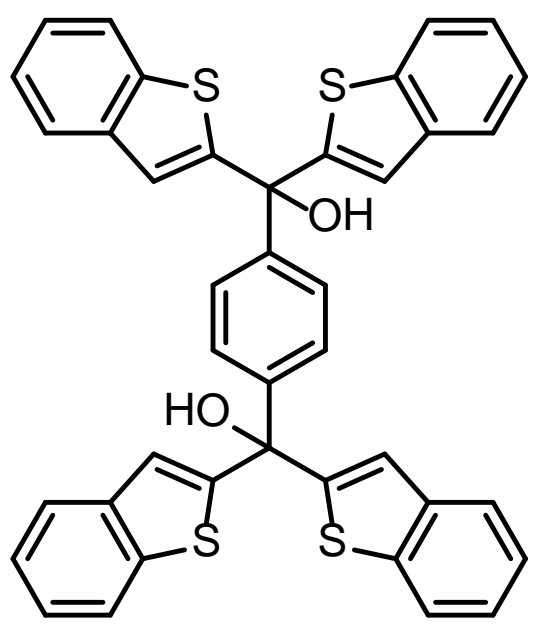

4

4a: 4" diethylamine (1:2)

4b: 4 "pyrrolidine $(1: 2)$

4c: 4 acetone $(1: 2)$

4d: 4 'DMF (1:2)

4e: 4 "1,4-dioxane (1:2)

Figure 1. Chemical formula structures of the studied diol hosts 3 and 4 including compounds of comparison $(\mathbf{1}, \mathbf{2})$ and specification of corresponding inclusion compounds.

Here, we present the synthesis of the new compounds $\mathbf{3}$ and $\mathbf{4}$, thoroughly report on their solid state inclusion behavior towards organic guests and provide a detailed discussion of their crystal structures. Thereby, the effect of the modified building elements is studied 
compared to previous model compounds. Moreover, compounds $\mathbf{3}$ and $\mathbf{4}$ have also been tested as solid coatings of a quartz crystal microbalance $(\mathrm{QCM})^{20}$ to reveal their potential in organic vapor sorption.

\section{RESULTS AND DISCUSSION}

Preparation of Host Compounds. Diols 3 and 4 were synthesized from 2-(benzo[b]thien-2yl)lithium (generated in situ by reaction of benzo[b]thiophene with $n$-butyllithium in dry THF at $-30{ }^{\circ} \mathrm{C}$, under argon) and dimethyl acetylenedicarboxylate (3) or dimethyl terephthalate (4), applying conventional addition procedures. ${ }^{21}$

Formation of Crystalline Inclusions. According to above considerations, replacement of the lateral 2-thienyl groups in $\mathbf{2}$ by the more voluminous benzo[b]thiophen-2-yl moieties such as in $\mathbf{3}$ or $\mathbf{4}$ is expected to distinctly increase the bulkiness of the host molecule providing potential advantages of the solid state inclusion behavior. Comparing $\mathbf{3}$ and $\mathbf{4}$, the central axle element is slightly longer in $\mathbf{4}$ (1,4-phenylene instead of ethynylene) but also more sterical demanding as compared to $\mathbf{3}$ featuring a slim ethynylene unit. All of these parameters should influence the inclusion of guest molecules making quite a distinction between $\mathbf{2}$ and $\mathbf{3}$ or $\mathbf{4}$, which is examined in the following.

Hence, $\mathbf{3}$ and $\mathbf{4}$ were crystallized from a series of solvents corresponding to those used for $\mathbf{2}^{17}$ that range from dipolar protic (alcohols, amines) via dipolar aprotic (DMSO, DMF, EtOAc, pyridine) to largely apolar species (chloroform, 1,4-dioxane, toluene) and involve solvents of acyclic and cyclic as well as aliphatic and aromatic or heteroaromatic nature. Both detailed specification of the solvents and findings obtained from this study are listed in Table 1. For comparison reasons, results previously achieved from 2 are also stated in the table. It emerges that both 3 and $\mathbf{4}$ are clearly superior to 2 (6 hits) in the number of inclusion compounds formed in the frame of the used solvents, although 4 (10 hits) is a little less efficient in comparison to 3 (12 hits). Another noticeable fact resulting from Table 1 is that both, $\mathbf{3}$ and $\mathbf{4}$, feature a definite preference to include the solvents in a 1:2 host:guest stoichiometry, while 2 crystallizes with solvents in varying stoichiometries ranging between 2:1, 1:1 and 1:2. Single exceptions for $\mathbf{3}$ and $\mathbf{4}$ are only the inclusions with EtOAc showing 1:1 and 3:2 stoichiometric ratios, respectively. Thus, correspondence of the 1:2 host:guest stoichiometric ratio with the bifunctionality of the host suggests, that in the inclusion compounds of $\mathbf{3}$ and $\mathbf{4}$ the number of 
host hydroxyls corresponds with the number of guest solvents. Despite the great many of inclusion compounds that have been isolated both of $\mathbf{3}$ and $\mathbf{4}$, inclusion seems to be limited to protic and distinctly polar solvents whereas apolar solvents are refrained from being included. This is another clear indication of the relevance of the host hydroxyl groups to guest binding. Although $\mathbf{3}$ and $\mathbf{4}$ are virtually conformable in the inclusion of aprotic polar solvents, there are distinct differences in their behavior considering protic guest species. This becomes obvious in the inclusion of alcohols, in particular with reference to the more voluminous alcohols $n$ $\mathrm{PrOH}$ and $n-\mathrm{BuOH}$ being accommodated in the crystal lattice of $\mathbf{3}$ unlike that of 4 . Remarkably, in this specific property, $\mathbf{3}$ is equivalent to the parent thiophene analogue 2 also yielding inclusion crystals of 1:2 host:guest stoichiometry. Hence, both uniformity and obvious differences distinguishing the inclusion behavior of $\mathbf{3}$ and $\mathbf{4}$, incorporating that of the previously reported parent host analogue $2,{ }^{17}$ justify a detailed X-ray crystallographic structural study performed of selected inclusion compounds obtained from $\mathbf{3}$ and $\mathbf{4}$.

X-ray Structural Study. Crystalline inclusion compounds which have been studied via X-ray structural analysis involve 3a (3 $\cdot n-\mathrm{BuOH}), 3 \mathbf{b}$ (3 $\cdot$ pyrrolidine), 3c (3 $\cdot$ acetone), 3d (3 DMSO), 3e (3 · DMF), 3f (3 · THF) as well as $\mathbf{4 a}$ (4 $\cdot$ diethylamine), $\mathbf{4 b}$ (4 $\cdot$ pyrrolidine), $\mathbf{4 c}$ (4 $\cdot$ acetone), 4d (4 $\cdot \mathrm{DMF})$ and $4 \mathrm{e}(4 \cdot 1$,4-dioxane), all being of 1:2 host:solvent stoichiometry (Fig. 1). In case of $\mathbf{4}$, we have been able to grow suitable crystals free of solvent making a reasonable comparison with corresponding inclusion compounds possible. Crystal and refinement data for the studied compounds are summarized in Table 2. Selected torsion angles of the molecules are listed in Table 3. Packing properties of the studied inclusion compounds are presented in Table 4 and relevant non-covalent interactions found in the crystal structures involving $\mathbf{3}$ and $\mathbf{4}$ are given in the Tables 5 and 6, respectively. Molecular structures of the inclusion compounds formed of $\mathbf{3}$ and $\mathbf{4}$, including the solvent-free structure of 4, are illustrated in Figures 2 and 3, corresponding packing diagrams and excerpts of packing modes are represented with Figures 4-7 and 8-10, respectively. 


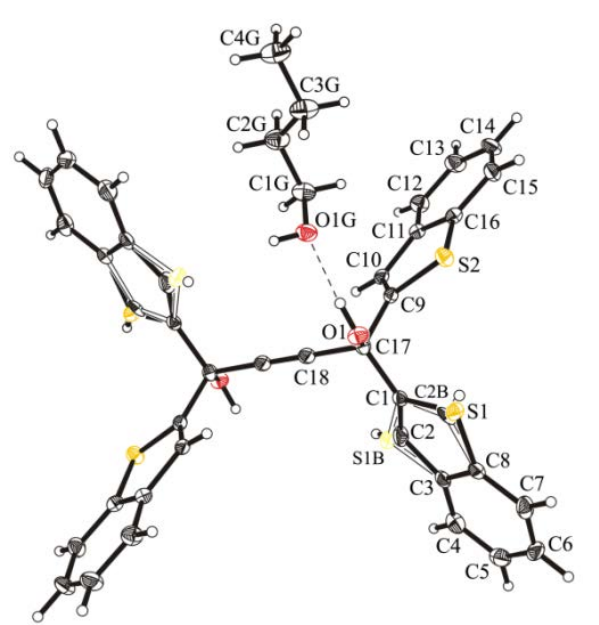

(a)

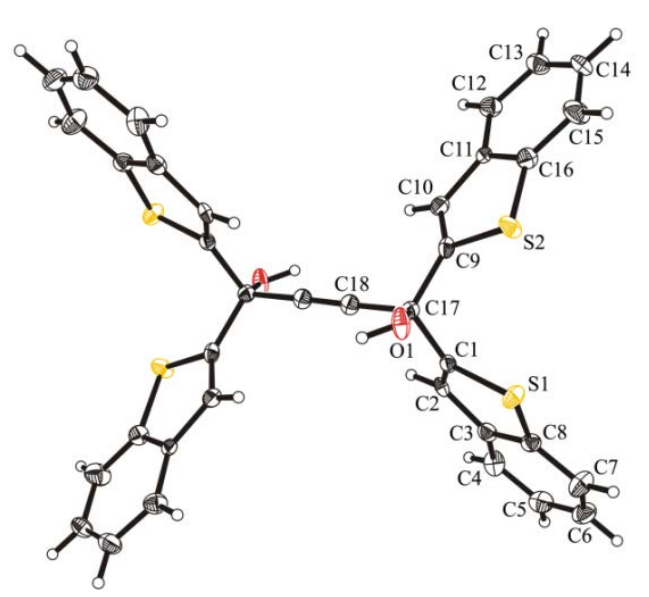

(c)

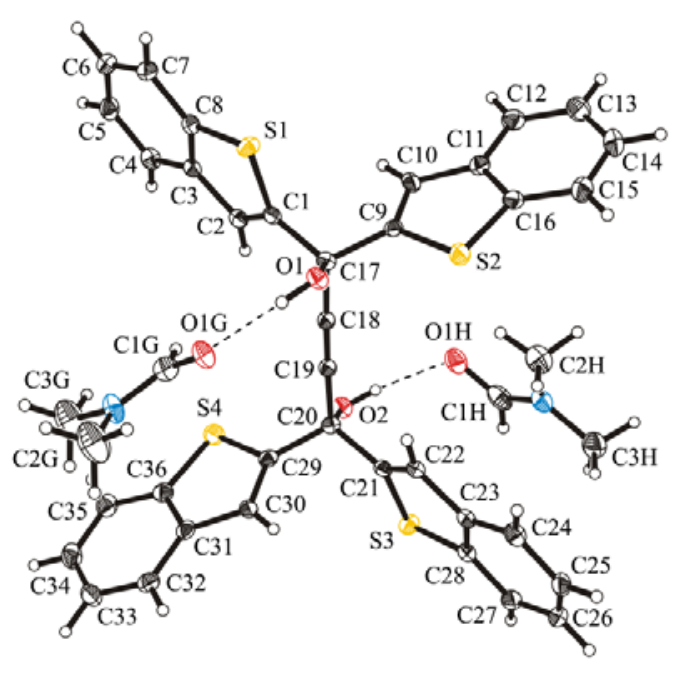

(e)

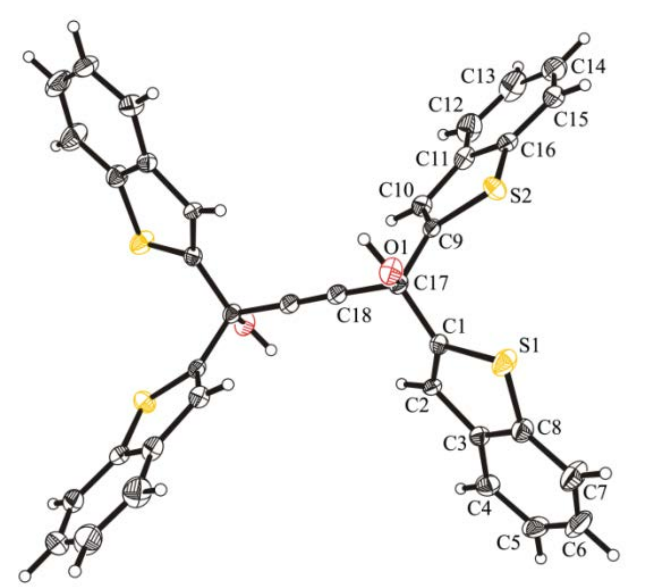

(b)

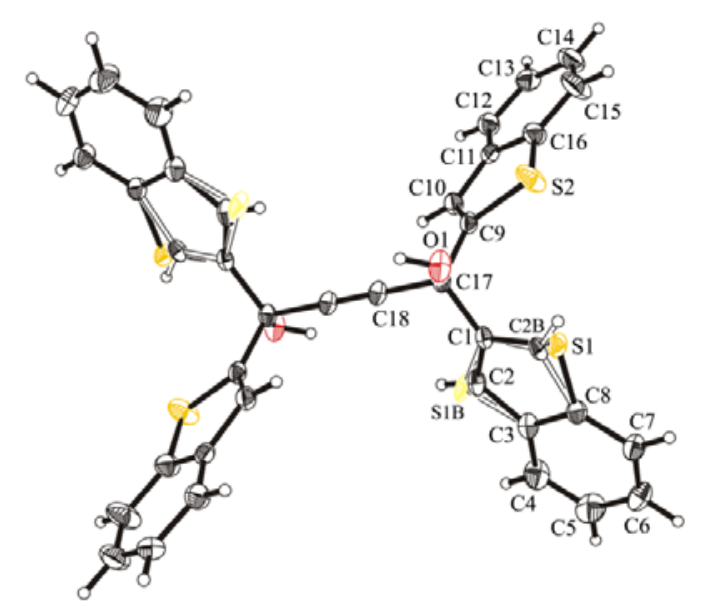

(d)

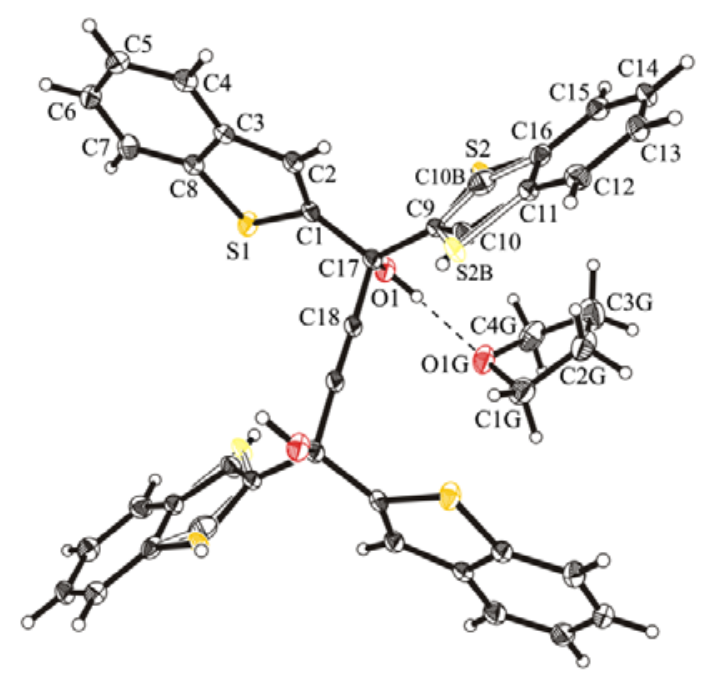

(f)

Figure 2. Molecular structures (ellipsoid-plot with $50 \%$ probability level) of the inclusion compounds 3a (a), 3b (b), 3c (c), 3d (d), 3e (e) and $\mathbf{3 f}$ (f) involving atom numbering scheme. The solvent molecules have been removed from structures $\mathbf{3 b} \mathbf{b} \mathbf{3} \mathbf{c}$ and $\mathbf{3 d}$ by the SQUEEZE method. 
Regarding 3, most of its inclusion compounds crystallize in the monoclinic space group $P 2_{1} / n$ (3a-3d) while $P 2_{1} / c$ and $P-1$ were found for $\mathbf{3 e}$ and $3 \mathbf{f f}$, respectively. Due to heavy disorder, the solvent molecules in $\mathbf{3 b}$ (pyrrolidine), 3c (acetone) and 3d (DMSO) have been removed from the structures; their asymmetric parts of the unit cell contain only half a host molecule depicted in Figure 2. In the inclusion compounds $\mathbf{3 a}$ and $\mathbf{3 f}$ also half an independent host molecule and an independent solvent molecule exist while the asymmetric part of the unit cell in the structure of 3e shows one host and two solvent molecules. Furthermore, one of the benzo[b]thiophene units each in $\mathbf{3 a}$ (sof $=0.78)$, 3d ( $\mathrm{sof}=0.91)$ and $\mathbf{3 f}$ ( $\mathrm{sof}=0.63$ ) is twofold disordered. The structures of solvent-free $\mathbf{4}$ and $\mathbf{4 b}$ crystallize in the triclinic space group $P-1$, while 4c, $4 \mathbf{d}$ and $4 \mathbf{e}$ were obtained in the monoclinic space group $P 2_{1} / c$ and $\mathbf{4 a}$ in $P 2_{1} / n$. The asymmetric parts of the unit cells of $\mathbf{4 a - 4 e}$ consist of half a host and one solvent molecule, whereas the solvent-free structure of $\mathbf{4}$ contains two halves of independent molecules (Figure 3). As before, twofold disorders of benzo[b]thiophene units have also been observed in the structures of $\mathbf{4 a}(\mathrm{sof}=0.75), \mathbf{4 b}(\mathrm{sof}=0.89,0.92), \mathbf{4 c}(\mathrm{sof}=0.77)$ and $4 \mathbf{e}(\mathrm{sof}=0.74,0.62)$. Moreover, the 1,4-dioxane molecule in the structure $\mathbf{4 e}$ is twice disordered with a site occupancy factor (sof) of 0.63 . 


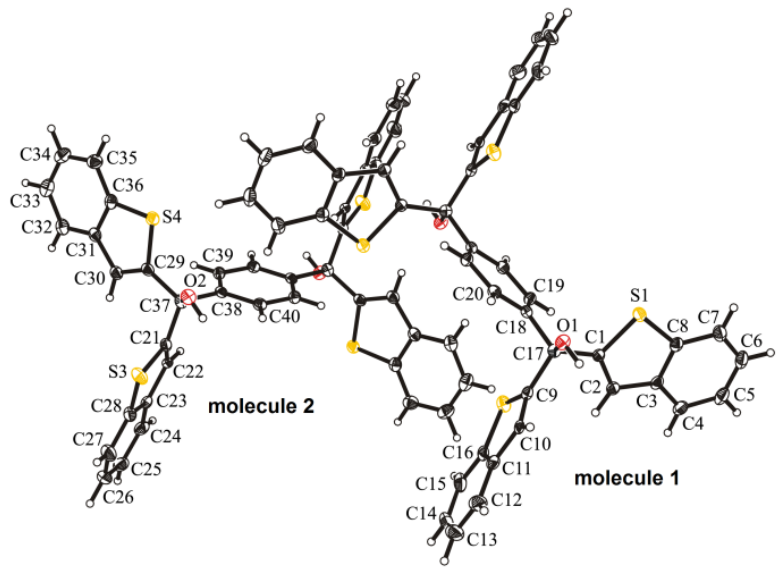

(a)

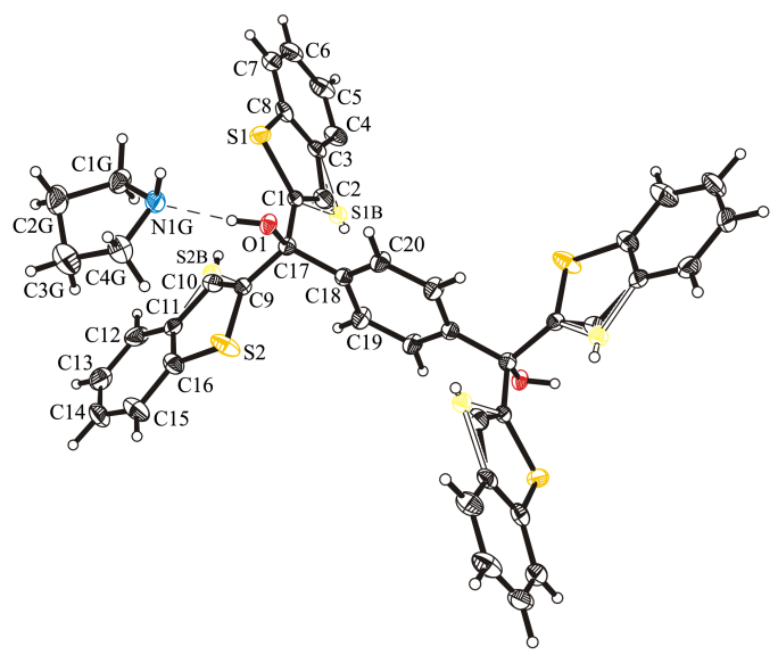

(c)

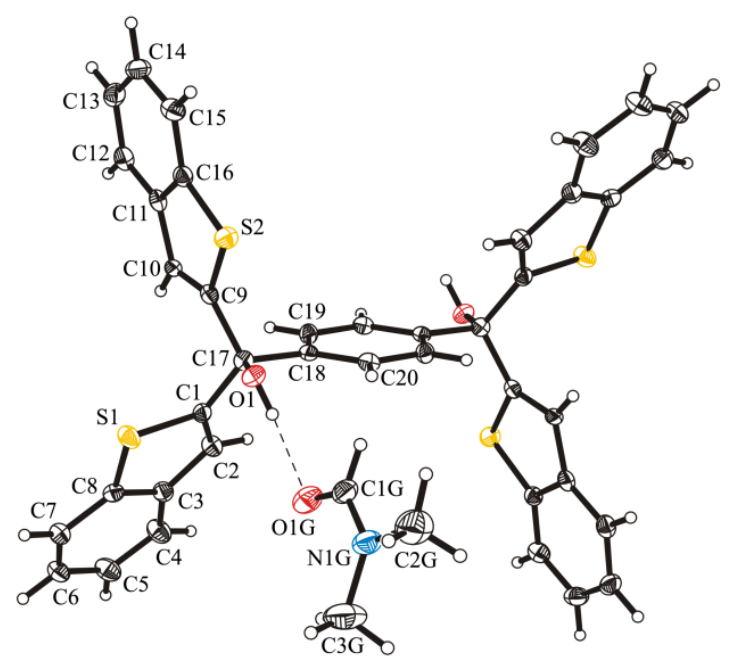

(e)

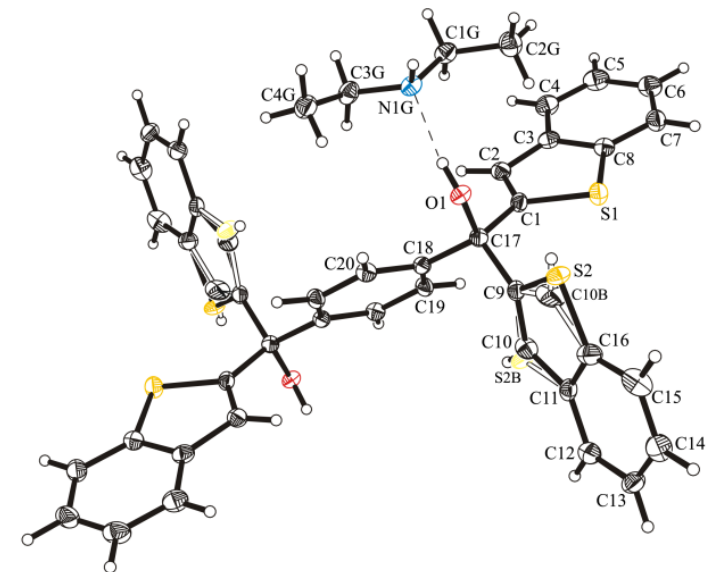

(b)

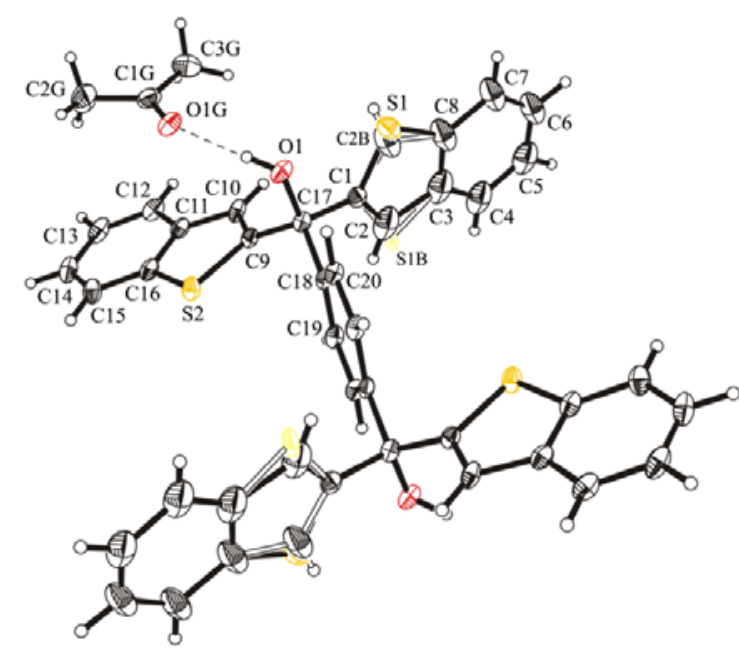

(d)

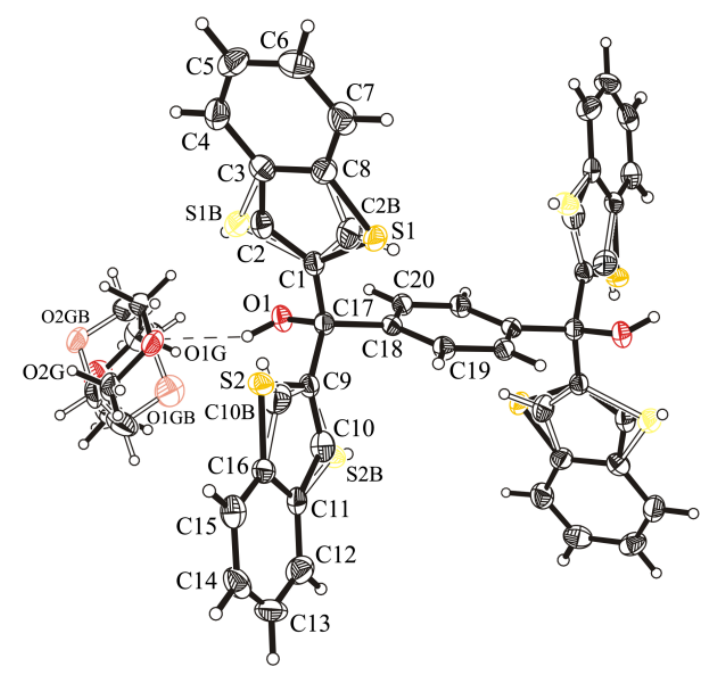

(f)

Figure 3. Molecular structures (ellipsoid-plot with 50 \% probability level) of the solventfree structure 4 (a) and the inclusion compounds $\mathbf{4 a}$ (b), $\mathbf{4 b}$ (c), 4c (d), $\mathbf{4 d}$ (e) and $\mathbf{4 e}$ (f) involving atom numbering scheme and specification of twofold disorder sites in $\mathbf{4 a}, \mathbf{4 b}, \mathbf{4 c}$ and $4 \mathbf{e}$. 
Molecular Structures. For the determination of the molecular conformations of the two hosts, we focused on the dihedral angles describing the relative position of the two benzo[b]thiophene units and the hydroxyl function. For $\mathbf{4}$, we also incorporated the linking phenylene unit. Relevant torsion angles of the host compound conformations in the crystal structures of $\mathbf{3}$ and $\mathbf{4}$ are summarized in Table 3. In $\mathbf{3}$, the angles of the triple bond range from $177.5^{\circ}$ in $\mathbf{3 f}$ to $179.8^{\circ}$ in $\mathbf{3 d}$, i.e. they deviate only insignificantly from $180^{\circ}$. The position of the heteroaromatic units in its different inclusion compounds, determined by the sequences S1-C1-C17-O1 and S2-C9-C17-O1, is more or less the same for 3a-3f indicating almost mirror symmetrical molecules. This is contrasted in $\mathbf{4}$, where the plane, aromatic linkers produce highly unsymmetrical host compounds, proven by a large variation of the respective torsion angles. In all structures of $\mathbf{4}$, the dihedral angles between the phenylene linker and the $\mathrm{OH}$ oxygen atoms (C20-C18-C17-O1) adopt rather small values (2.6 - $\left.35.5^{\circ}\right)$, i.e. a periplanar arrangement is observed.

In all of the studied crystal structures of $\mathbf{3}$ and $\mathbf{4}$, the hydrogens of the $\mathrm{OH}$ groups are not involved in any intramolecular interaction. Hence, the conformational fixation in all hosts is restricted to weaker $\mathrm{S} \cdots \mathrm{O}-$-ontacts $^{22}[\mathrm{~d}(\mathrm{~S} \cdots \mathrm{O})=2.741(2)-3.107(2) \AA]$, while in the structures 3c, 3d, 4a and 4b intramolecular S $\cdots S$ - contacts $^{23,24}[d(S \cdots S)=3.444(2)-3.545(2) \AA]$ appear additionally. Besides that, we were able to pinpoint two C-H $\cdots$ S-contacts ${ }^{25}$ [4: $\mathrm{d}(\mathrm{C} 2 \cdots \mathrm{S} 2)=3.393(2) \AA$ and 4c: $\mathrm{d}(\mathrm{C} 19 \cdots \mathrm{S} 1 \mathrm{~B})=3.332(5) \AA]$.

Packing structures. As shown by the packing property of the studied crystal structures given in Table 4, it is evident that though all the structures possess a 1:2 host:guest stoichiometry, different parts of the unit cell are occupied by guest molecules. This is not only depending on the guest dimensions but also on the complementary of the host and guest species. With reference to these data, i.e. solvent accessible void (SAV), Kitaigorodskii packing index $(\mathrm{KPI})^{26}$ and derived from these data percentaged part of the unit cell and channel size, the DMSO inclusion compound 3d, occupying the largest percentaged part of the structure unit cells (37.9\%), shows accordingly the smallest KPI value of $47.5 \%$ without guest molecules. Hence, the least closed packing of the studied inclusion compounds is presented of structure 3d. Values close to that of 3d have only been observed for $3 \mathbf{b}$ (KPI=49.2 \%) and 3c (KPI=49.6\%). Unfortunately, determination of the KPI values including the guest molecules could not be carried out for these structures due to the necessity of removal of the highly disordered guests from the structures. On the other side, 4c (with acetone) and $\mathbf{4 e}$ (with 1,4dioxane) having percentaged parts of the unit cell of 25.5 and $26.4 \%$, respectively, feature a 
closed packing which is confirmed by the corresponding KPI values of 57.0 and $55.2 \%$ without guests. For $\mathbf{4 e}$, this is also sustained by the KPI of $71.2 \%$ considering inclusion of the guest molecules. However, the KPI value for 4c of only $69.5 \%$ is smaller than expected in view of the rather high KPI (57.0 \%) without guests. This suggests that the host molecules seem to be much more closed packed than the included acetone molecules. However, looking at the overall data, the majority of the present inclusion compounds possess percentaged parts of the unit cell that range between 28.0 and $29.6 \%$ which is attended by KPI values being in the order of 52.3 to $54.8 \%$ without guests or 67.2 and $70.4 \%$ including the guests, respectively.

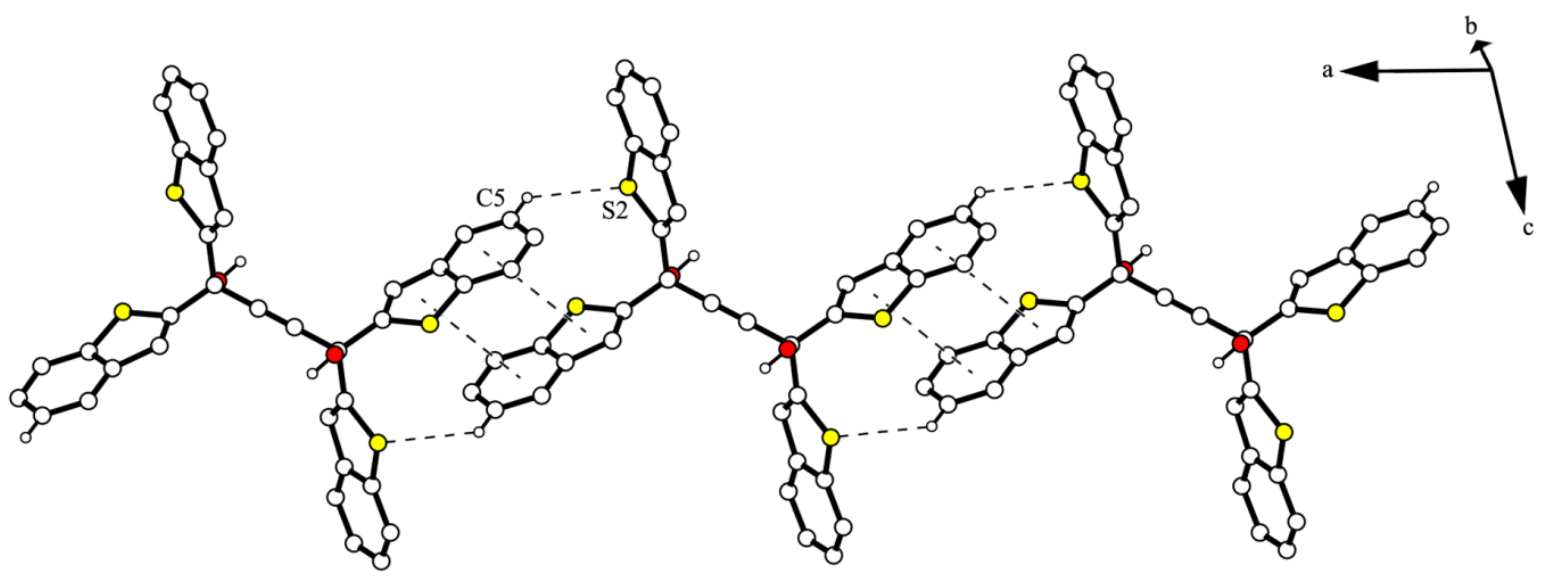

(a)

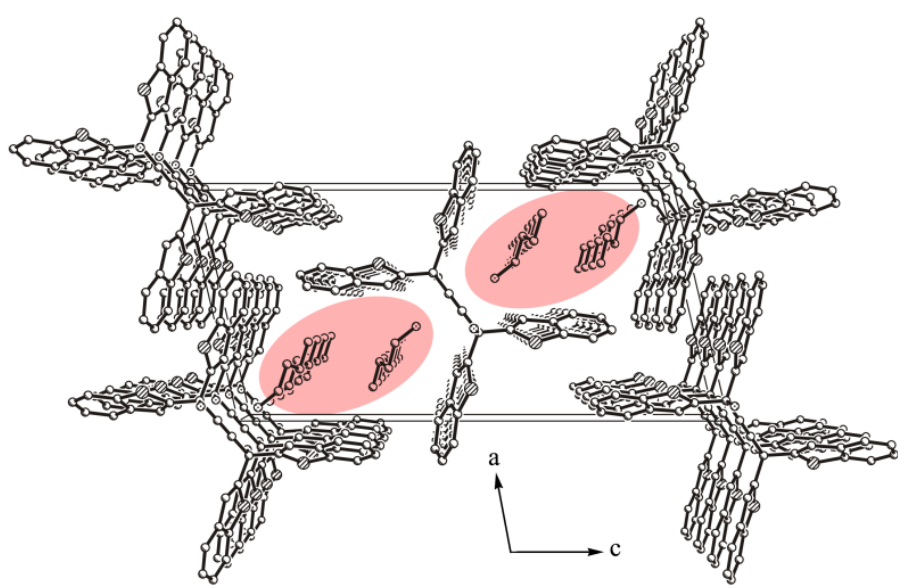

(b)

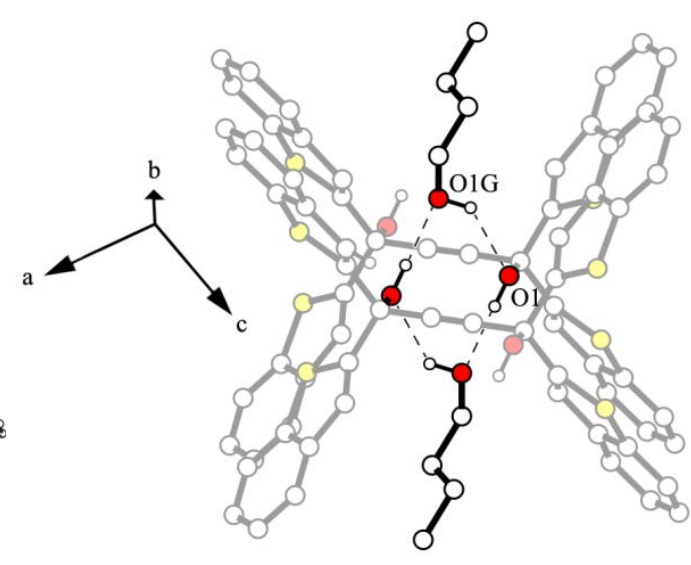

(c)

Figure 4. Illustrations of the structure 3a: (a) Chain-like connection of the host molecules via $\pi \cdots \pi$-interactions and $\mathrm{C}-\mathrm{H} \cdots \mathrm{S}$-contacts shown with broken lines. (b) Hydrogen bond ring motif involving the $\mathrm{OH}$ groups of the host and guest species. (c) Van-der-Waals model with solvent channels highlighted. (d) Packing structure including channels filled with $n$-BuOH. Non-relevant H-atoms have been omitted for clarity. 
Regarding a more detailed discussion on the molecular arrangement including a description of intermolecular interaction modes, the structures can be specified as follows. In the structure of the inclusion compound 3a with $n-\mathrm{BuOH}$, the host molecules are chain-like connected along the $a$ axis by $\pi \cdots \pi$-interactions ${ }^{27,28}$ of the benzo[b]thiophene units and by C-

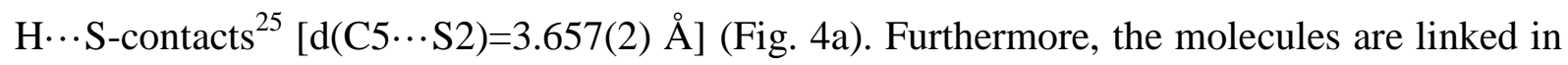
chains along the $b$ axis including the $n$ - $\mathrm{BuOH}$ molecules (Fig. 4b). In keeping with their distinct hydrogen bond donor and acceptor property, they are involved in strong O-H $\cdots \mathrm{O}-$ hydrogen bonding $[\mathrm{d}(\mathrm{O} 1 \cdots \mathrm{O} 1 \mathrm{G})=2.676(2) \AA, \mathrm{d}(\mathrm{O} 1 \mathrm{G} \cdots \mathrm{O} 1)=2.777(2) \AA]$ between host and guest $\mathrm{OH}$ groups giving rise to a well-known cyclic hydrogen bond motif with the graph set $\mathrm{R}_{4}^{4}(8)^{29,30}$ (Fig. 4c). In addition, C-H $\cdots \mathrm{O}^{31}[\mathrm{~d}(\mathrm{C} 10 \cdots \mathrm{O} 1 \mathrm{G})=3.501(3) \AA]$ as well as C-H $\cdots \mathrm{S}-$ contacts $[\mathrm{d}(\mathrm{C} 1 \mathrm{G} \cdots \mathrm{S} 1 \mathrm{~B})=3.528(8) \AA]$ are found between the host and guest moieties. Due to the disorder of the benzo[b]thiophene rings, the latter contacts exist only to $22 \%$ in the structure. Furthermore, van-der-Waals interactions seem to exist between the alkyl chains of the $n$-BuOH molecules.

Remarkably, the crystal structures of the inclusion compounds $3 \mathbf{b}$ (pyrrolidine), 3c (acetone) and 3d (DMSO) feature nearly the same cell parameters and base on comparable interactions in the packing though these solvents are rated rather different in respect of proton donor behavior. Along the crystallographic $b$-axis, the host molecules are connected by weak $\mathrm{C}-\mathrm{H} \cdots \mathrm{O}$-hydrogen bonds, ${ }^{31}$ between the methine units $\mathrm{C} 12-\mathrm{H} 12$ (3b) as well as $\mathrm{C} 4-\mathrm{H} 4$ (3c, 3d) and the hydroxyl oxygen $\mathrm{O} 1[\mathrm{~d}(\mathrm{C} 12 \cdots \mathrm{O} 1)=3.420(3) \AA(3 \mathbf{b}), \mathrm{d}(\mathrm{C} 4 \cdots \mathrm{O} 1)=3.334(5) \AA$ (3c) and 3.374(2) $\AA$ (13d)]. Moreover, in the case of the acetone and DMSO inclusions, the host molecules are stabilized in [111]-direction by weak $\mathrm{C}-\mathrm{H} \cdots \pi$-interactions ${ }^{32,33}$ formed between the methine groups $\mathrm{C} 13-\mathrm{H} 13, \mathrm{C} 14-\mathrm{H} 14, \mathrm{C} 15-\mathrm{H} 15$ and the $\pi$ systems $\mathrm{Cg} 1, \mathrm{Cg} 3$, Cg5, respectively. By way of contrast, in the pyrrolidine inclusion $3 \mathbf{b}$, the methine units C5H5, C6-H6, C7-H7 interact with the $\pi$-systems Cg2, Cg4, Cg5, respectively. However, in direction of the $a$-axis non-covalent contacts between the host molecules are not observed; only the linkage to the guest species is evident. Consequently, the structures $\mathbf{3 b}, \mathbf{3 c}$ and $\mathbf{3 d}$ contain almost identical solvent channels filled by the corresponding guest molecules (exemplary pictured for $\mathbf{3 b}$ in Fig. 5 and for 3a, 3c and 3d in Fig. S1 in the Supporting Information), probably being stabilized via hydrogen bonding between the host $\mathrm{OH}$ groups and the carbonyl, sulfoxyl as well as amino units of the solvent molecules, respectively. 

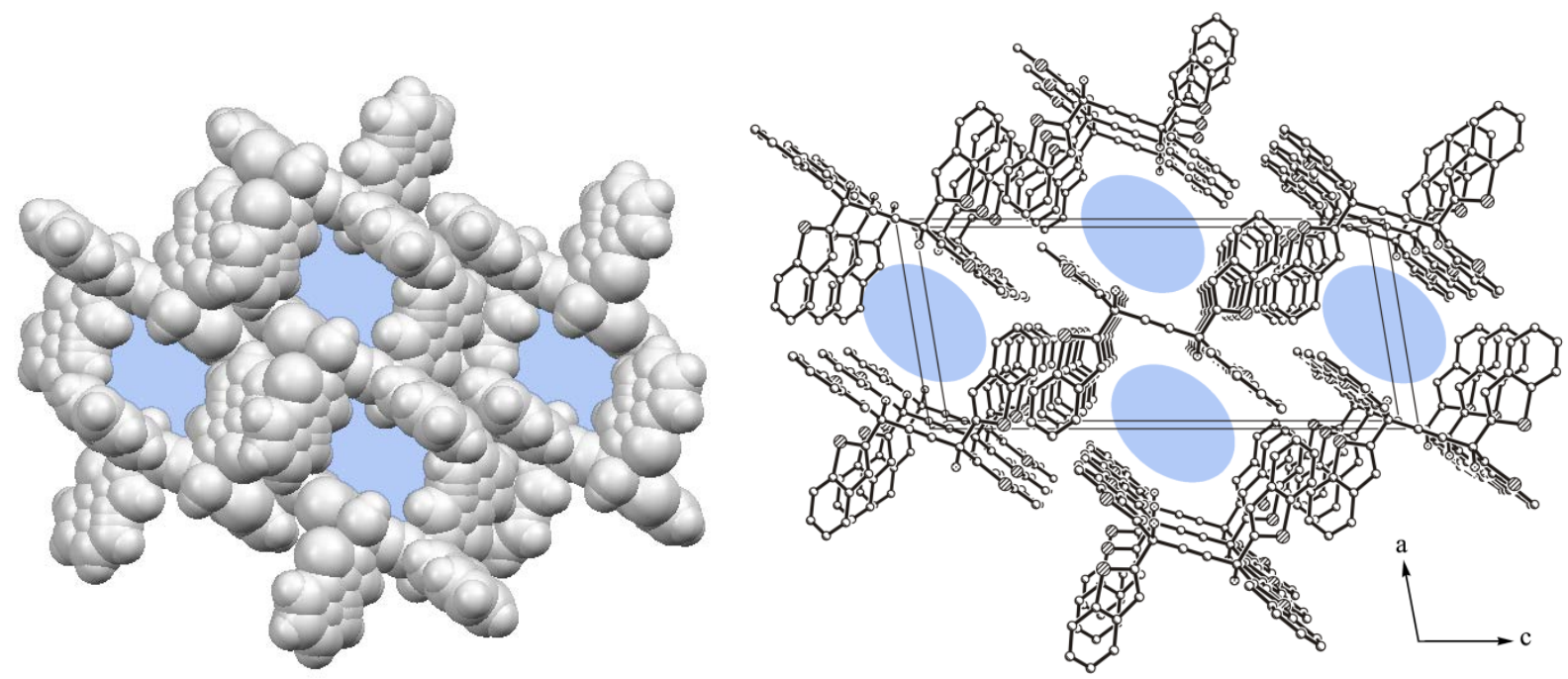

Figure 5. Van-der-Waals models and packing structures of the inclusion compounds $\mathbf{3 b}$ (a), 3c (b) and 3d (c). H-atoms in the packing structure have been omitted for clarity. Solvent channels are highlighted.

Owing to weak $\mathrm{C}-\mathrm{H} \cdots \mathrm{O}$-contacts $[\mathrm{d}(\mathrm{C} 12 \cdots \mathrm{O} 1)=3.350(3) \AA$ and $\mathrm{d}(\mathrm{C} 32 \cdots \mathrm{O} 2)=$ 3.352(3) $\AA$ ] between the host molecules in 3e, we found layers parallel to the (001)-plain (Fig. 6a) with the molecules alternately oriented lengthwise and diagonally, relating to the alkyne unit, along the [110]- and [1-10]-directions. In addition, $\mathrm{C}-\mathrm{H} \cdots \pi$-interactions $[\mathrm{d}(\mathrm{C} 4 \cdots \mathrm{Cg} 8)=$ 3.433(2) $\AA, \mathrm{d}(\mathrm{C} 24 \cdots \mathrm{Cg} 4)=3.437(2) \AA, \mathrm{d}(\mathrm{C} 15 \cdots \mathrm{Cg} 1)=3.617(2) \AA]$ take part in the layer formation. The host layers are linked among each other via pairs of DMF guest molecules (Fig. 6b) developing strong $\mathrm{O}-\mathrm{H} \cdots \mathrm{O}$-hydrogen bonds $[\mathrm{d}(\mathrm{O} 1 \cdots \mathrm{O} 1 \mathrm{G})=2.681(2) \AA$, $\mathrm{d}(\mathrm{O} 2 \cdots \mathrm{O} 1 \mathrm{H})=2.713(2) \AA]$ while the dimers of DMF molecules are linked by weak $\mathrm{C}-$ $\mathrm{H} \cdots \mathrm{O}$-hydrogen bonding $[\mathrm{d}(\mathrm{C} 3 \mathrm{H} \cdots \mathrm{O} 1 \mathrm{H})=3.485(3) \AA$, d(C3G $\cdots \mathrm{O} 1 \mathrm{G})=3.582(4) \AA]$ (Fig. 6c). Further host-guest stabilization originates from $\mathrm{C}-\mathrm{H} \cdots \mathrm{O}$-interactions including aromatic methine groups and the guest carbonyl units $[\mathrm{d}(\mathrm{C} 7 \cdots \mathrm{O} 1 \mathrm{H})=3.274(3) \AA, \mathrm{d}(\mathrm{C} 13 \cdots \mathrm{O} 1 \mathrm{G})=$ 3.343(3) $\AA$ ] as well as from $\mathrm{C}-\mathrm{H} \cdots \pi$-contacts between the DMF methyl groups and the benzo[b]thiophene units $[\mathrm{d}(\mathrm{C} 3 \mathrm{H} \cdots \mathrm{Cg} 5)=3.536(3) \AA$, $\mathrm{d}(\mathrm{C} 3 \mathrm{G} \cdots \mathrm{Cg} 6)=3.411(4) \AA$, $\mathrm{d}(\mathrm{C} 2 \mathrm{G} \cdots \mathrm{Cg} 1)=3.320(3) \AA]$. Thus, the formamide oxygens O1G and O1H are involved in an inverse trifurcated connection. 
(a)

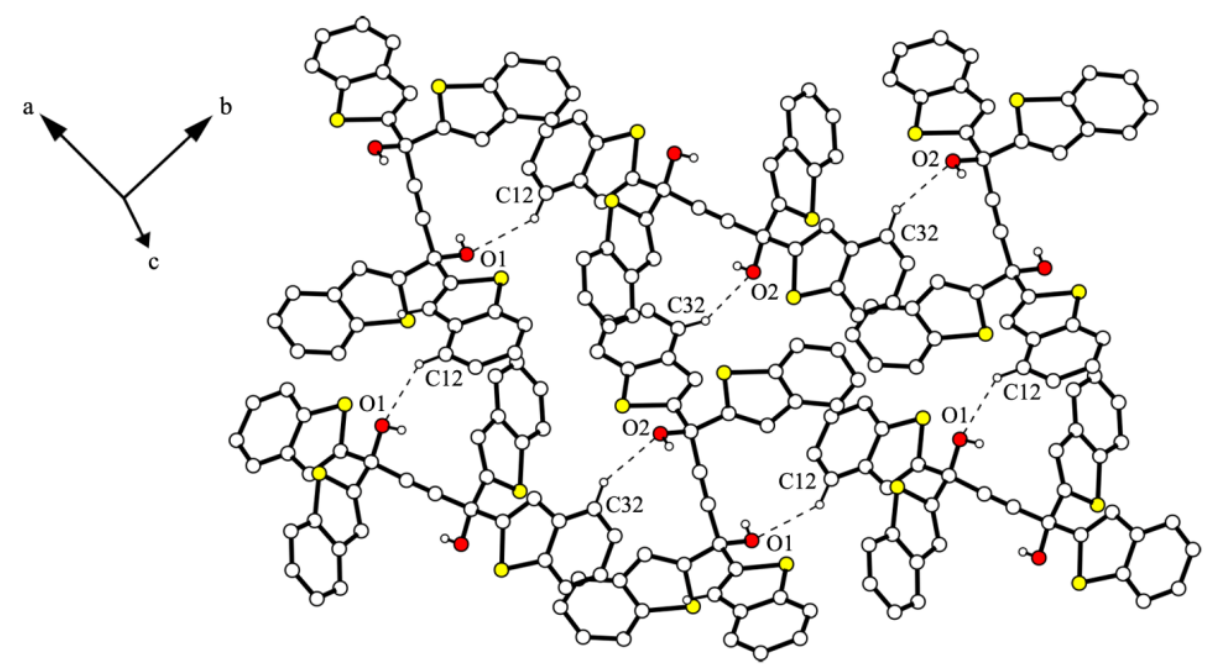

(b)

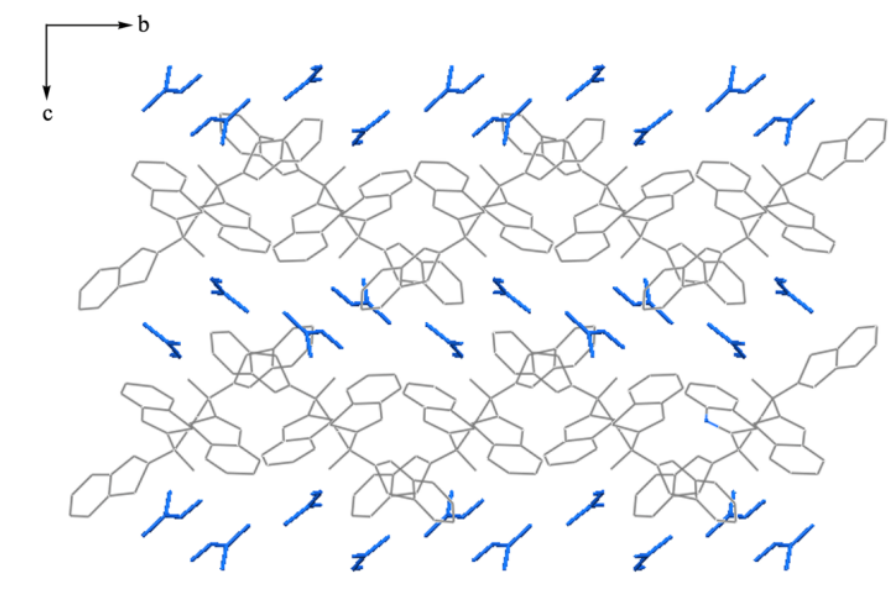

(c)

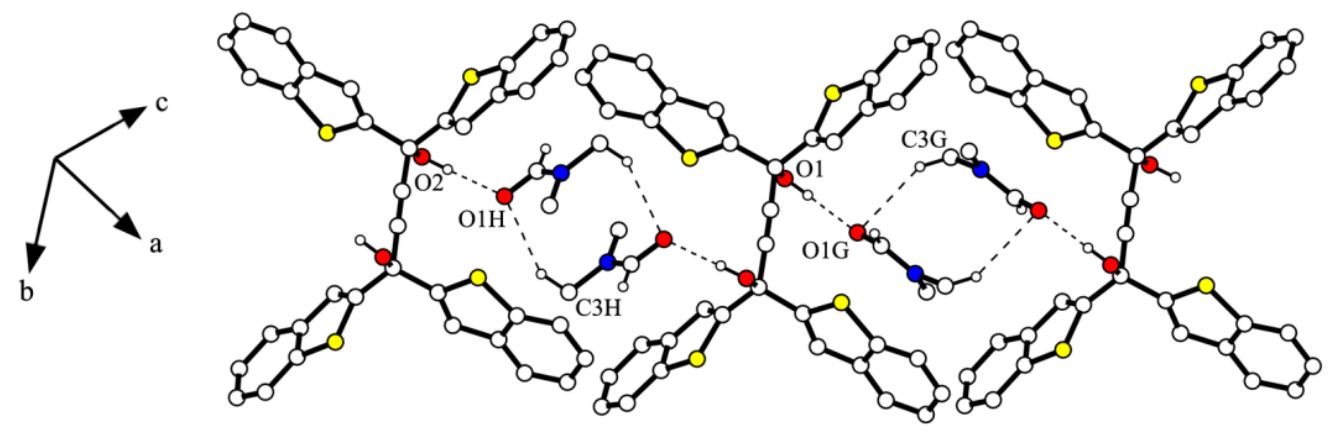

Figure 6. Illustrations of the structure 3e: (a) Linkage of the host molecules within the layer structure by $\mathrm{C}-\mathrm{H} \cdots \mathrm{O}$-hydrogen bonds. (b) Packing structure showing layers of host and guest species, respectively. (c) DMF dimers stabilized via $\mathrm{C}-\mathrm{H} \cdots \mathrm{O}$-interactions and connection of the host and guest molecules by $\mathrm{O}-\mathrm{H} \cdots$ O-hydrogen bonds. Non-relevant $\mathrm{H}-$ atoms have been omitted for clarity. 
In the THF inclusion compound 3f, the host molecules are arranged in strands along the crystallographic $a$-axis making use of weak $\mathrm{C}-\mathrm{H} \cdots \mathrm{O}$-hydrogen bonding $[\mathrm{d}(\mathrm{C} 4 \cdots \mathrm{O} 1)=$

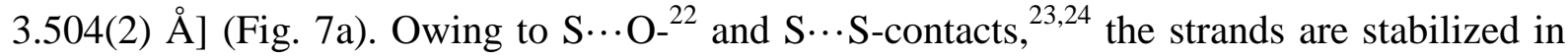
$b$-direction while along the $c$-axis $\mathrm{C}-\mathrm{H}^{\cdots} \mathrm{S}^{25}[\mathrm{~d}(\mathrm{C} 14 \cdots \mathrm{S} 1)=3.667(2) \AA]$ and $\mathrm{C}-\mathrm{H}^{\cdots} \pi-$ interactions $^{32,33}[\mathrm{~d}(\mathrm{C} 5 \cdots \mathrm{Cg} 5)=3.666(2) \AA]$ occur in between. The THF guest molecules included in cage-like voids (Fig. 7b, Fig. S2) are fixed by strong $\mathrm{O}-\mathrm{H} \cdots \mathrm{O}$-hydrogen bonds $[\mathrm{d}(\mathrm{O} 1 \cdots \mathrm{O} 1 \mathrm{G})=2.681(2) \AA]($ Fig. $7 \mathrm{a})$ as well as $\mathrm{C}-\mathrm{H} \cdots \pi-[\mathrm{d}(\mathrm{C} 2 \mathrm{G} \cdots \mathrm{Cg} 4)=3.738(2) \AA$, $\mathrm{d}(\mathrm{C} 3 \mathrm{G} \cdots \mathrm{Cg} 2)=3.730(2) \AA, \mathrm{d}(\mathrm{C} 4 \mathrm{G} \cdots \mathrm{Cg} 4)=3.916(2) \AA]$ and $\mathrm{C}-\mathrm{H} \cdots \mathrm{S}$-interactions $[\mathrm{d}(\mathrm{C} 4 \mathrm{G} \cdots \mathrm{S} 2)=3.836(2) \AA]$.

(a)

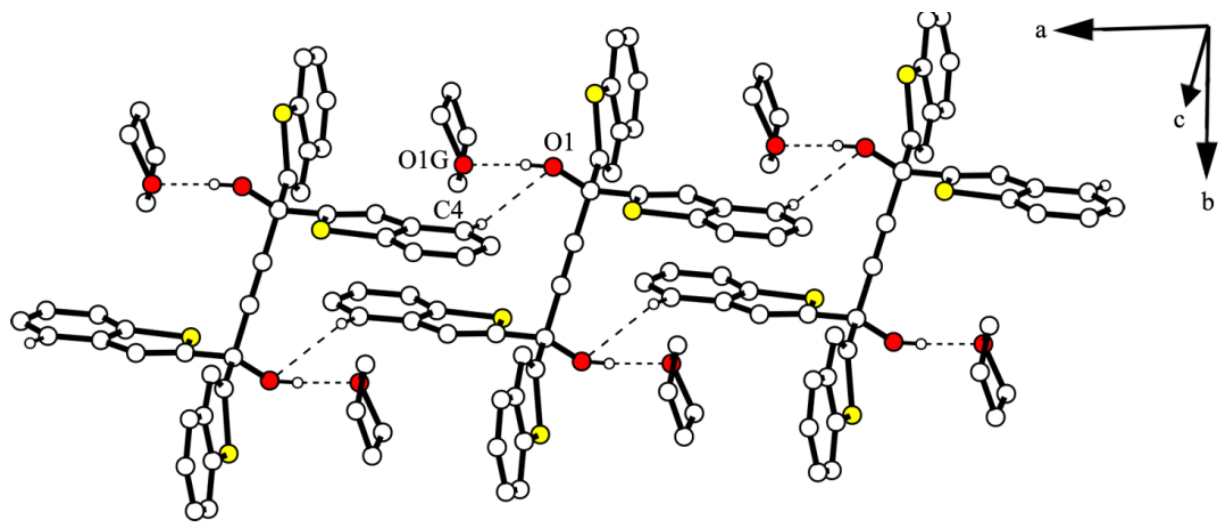

(b)

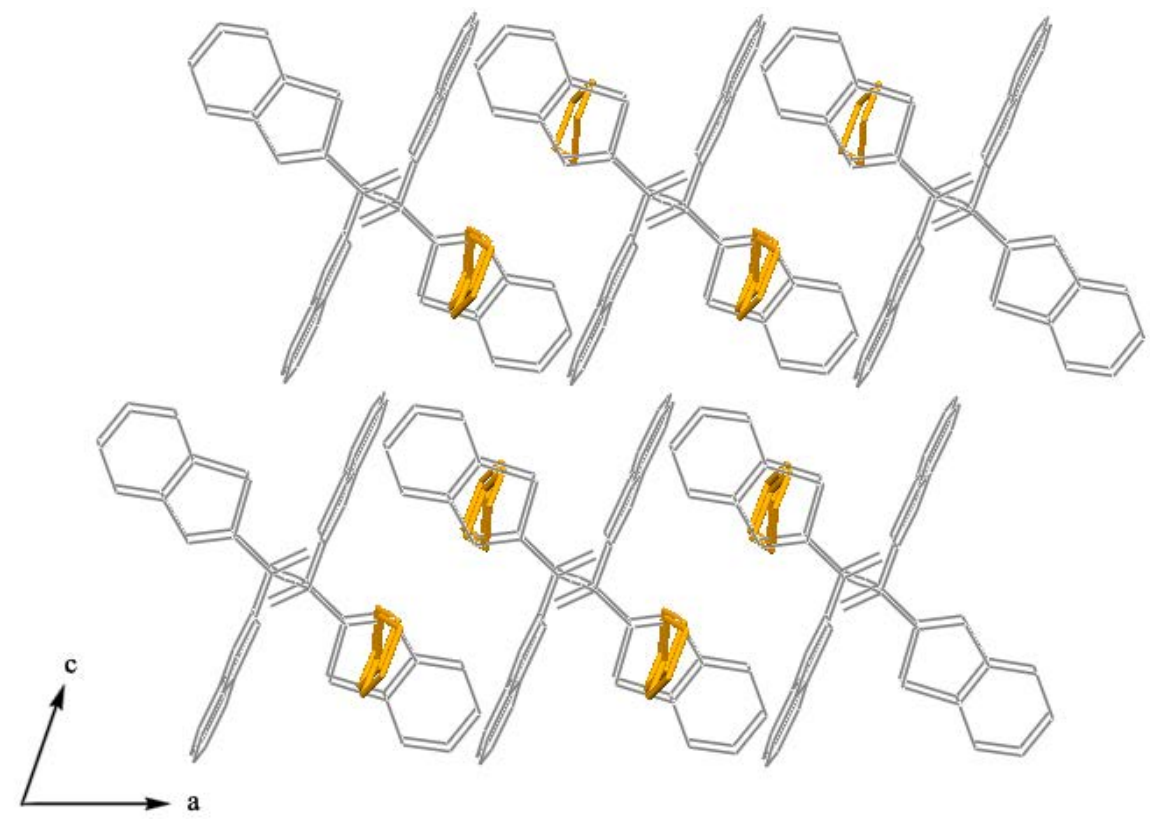

Figure 7. Illustrations of the structure 3f: (a) Strand of host and THF guest molecules connected via $\mathrm{C}-\mathrm{H} \cdots \mathrm{O}-$ and $\mathrm{O}-\mathrm{H} \cdots \mathrm{O}-$ hydrogen bonds, respectively. (b) View of the cagelike packing structure in the direction of the $b$ - and $a$-axis. 
Having the opportunity to isolate a suitable solvent free crystal of $\mathbf{4}$, we have been able to get an insight into the packing behavior of $\mathbf{4}$ without the influencing control of solvent interaction. In the structure, the two independent diol molecules (Fig. 3a) are arranged in separate layers parallel to the (100)-plane. The molecules possessing the conformation- 1 show stabilization along the $a$-axis by $\mathrm{C}-\mathrm{H} \cdots \pi$-contacts $[\mathrm{d}(\mathrm{C} 5 \cdots \mathrm{Cg} 2)=3.577(2) \AA$ ], while in $b$ direction $\pi \cdots \pi$ interactions ${ }^{27,28}[\mathrm{~d}(\mathrm{Cg} 2 \cdots \mathrm{Cg} 4)=3.971(2) \AA]$ are found (Fig. 8a). By way of contrast, the molecules of conformation-2 are linked in $c$-direction via $\mathrm{C}-\mathrm{H} \cdots \mathrm{S}$-contacts $[\mathrm{d}(\mathrm{C} 33 \cdots \mathrm{S} 3)=3.741(2) \AA]$ and as before supportive $\pi \cdots \pi$ interactions $[\mathrm{d}(\mathrm{Cg} 5 \cdots \mathrm{Cg} 7)=$ 3.950(2) $\AA$ ] along the $b$-axis. These separate layers featuring different conformations are arranged alternately in direction of the crystallographic $a$-axis (Fig. 8b) connected among each other by an accumulation of $\mathrm{O}-\mathrm{H} \cdots \pi$-contacts $^{34}[\mathrm{~d}(\mathrm{O} 1 \cdots \mathrm{Cg} 9)=3.483(1) \AA$, $\mathrm{d}(\mathrm{O} 2 \cdots \mathrm{Cg} 1)=3.339(1) \AA]$, weak $\mathrm{C}-\mathrm{H} \cdots \mathrm{O}-$ hydrogen bonds $[\mathrm{d}(\mathrm{C} 30 \cdots \mathrm{O} 1)=3.599(2) \AA]$ and $\mathrm{C}-\mathrm{H} \cdots \mathrm{S}$-interactions $[\mathrm{d}(\mathrm{C} 22 \cdots \mathrm{S} 1)=3.607(2) \AA \AA, \mathrm{d}(\mathrm{C} 2 \cdots \mathrm{S} 3)=3.393(2) \AA]$.

(a)

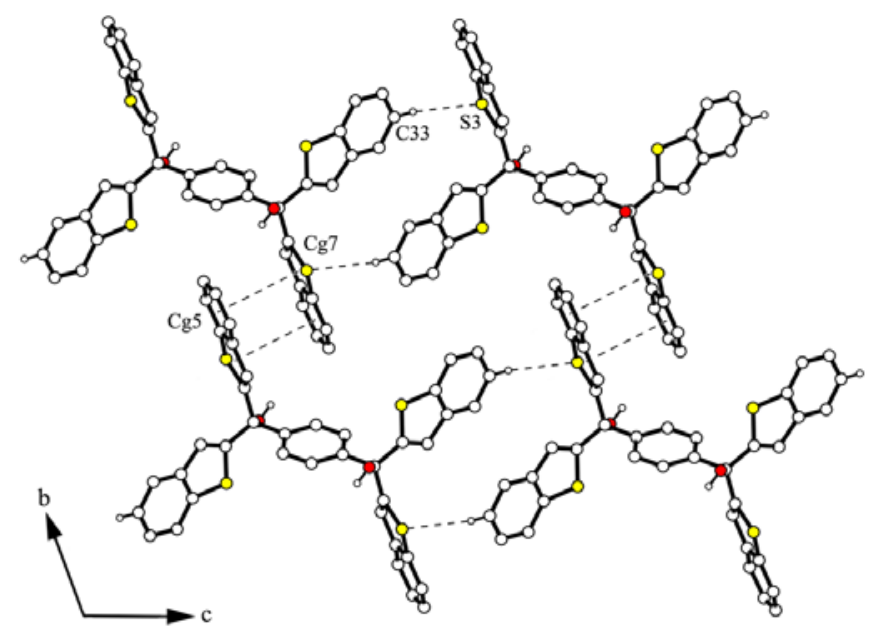

(b)

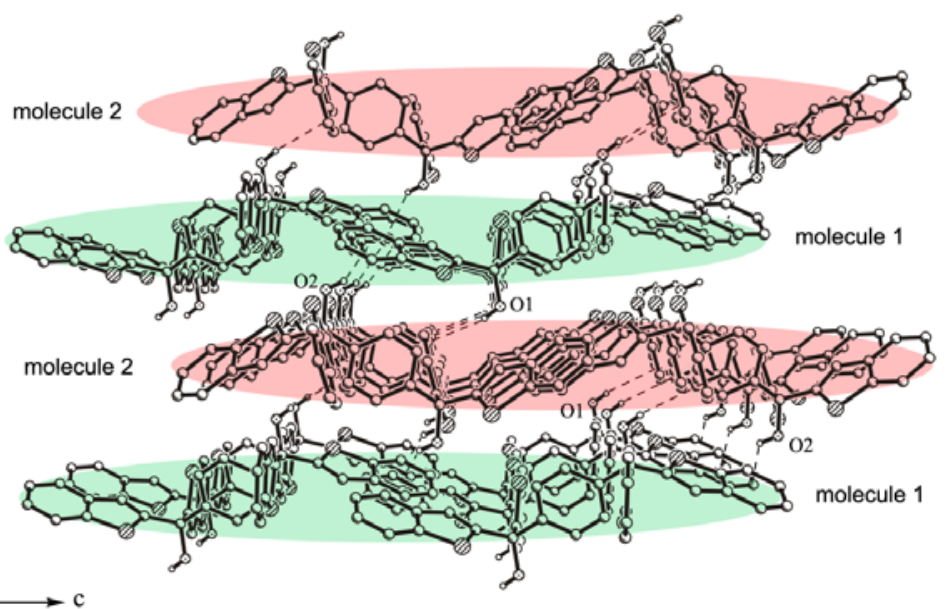

Figure 8. Illustrations of the structure 4: (a) Layer of molecules in conformation-1 parallel to the (100)-plain involving $\mathrm{C}-\mathrm{H} \cdots \mathrm{S}$ - and $\pi \cdots \pi$-interactions. (b) Packing structure 
showing alternately arranged layers of molecules being connected by $\mathrm{O}-\mathrm{H} \cdots \pi$-contacts. Nonrelevant $\mathrm{H}$-atoms have been omitted for clarity.

For all the crystals of the inclusion compounds of 4 (4a-4e), a strand-like connection of the host molecules along the crystallographic $b$-axis is recognized to be a common structural characteristic. This involves weak $\mathrm{C}-\mathrm{H} \cdots \pi$-interactions for $\mathbf{4 a}, \mathbf{4 b}, \mathbf{4} \mathbf{c}$ and $\mathbf{4 e}$ as well as $\mathrm{C}-\mathrm{H} \cdots \mathrm{S}$-contacts in the case of $\mathbf{4 d}$. In addition, $\mathrm{S} \cdots \mathrm{S}$-interactions between the benzo[b]thiophene units occur in the strands of $\mathbf{4 c}$ and $\mathbf{4 e}$. In the $c$-direction, the molecule strands of the structures, except for $\mathbf{4 a}$, are stabilized via $\mathrm{C}-\mathrm{H} \cdots \pi$-interactions while in $\mathbf{4 a}$ van-der-Waals-interactions are a prime factor and additionally $\mathrm{C}-\mathrm{H} \cdots \mathrm{S}$-contacts take part in stabilization of the structures $\mathbf{4 a}, \mathbf{4 b}$ and $\mathbf{4 d}$. Considering connections along the $a$-axis, some differences are obvious. In the inclusion compounds $4 \mathbf{a}$ and $\mathbf{4 d ~} \mathrm{C}-\mathrm{H} \cdots \pi$-hydrogen bonds link the molecules whereas in $\mathbf{4} \mathbf{e} \mathrm{C}-\mathrm{H} \cdots \mathrm{S}$-contacts occur. Regarding the structures $\mathbf{4 b}$ and $\mathbf{4} \mathbf{c}$, $\mathrm{S} \cdots$ S-interactions stabilize the host moieties and additional $\mathrm{C}-\mathrm{H} \cdots \mathrm{O}$-hydrogen bonds are formed only in $\mathbf{4 c}$. Consequently, cage-like voids of host entities are created (4a, $\mathbf{4 b}, \mathbf{4} \mathbf{c}$ and 4e) with the guest molecules being included there. However, in $\mathbf{4 d}$ the DMF guests are located in channels along the $b$-axis. Representative examples for both these inclusion topologies are illustrated in Fig. 9 for $\mathbf{4 a}$ and $\mathbf{4 d}$, while others are found in the supporting information (Figs. S3 and S4).

(a)

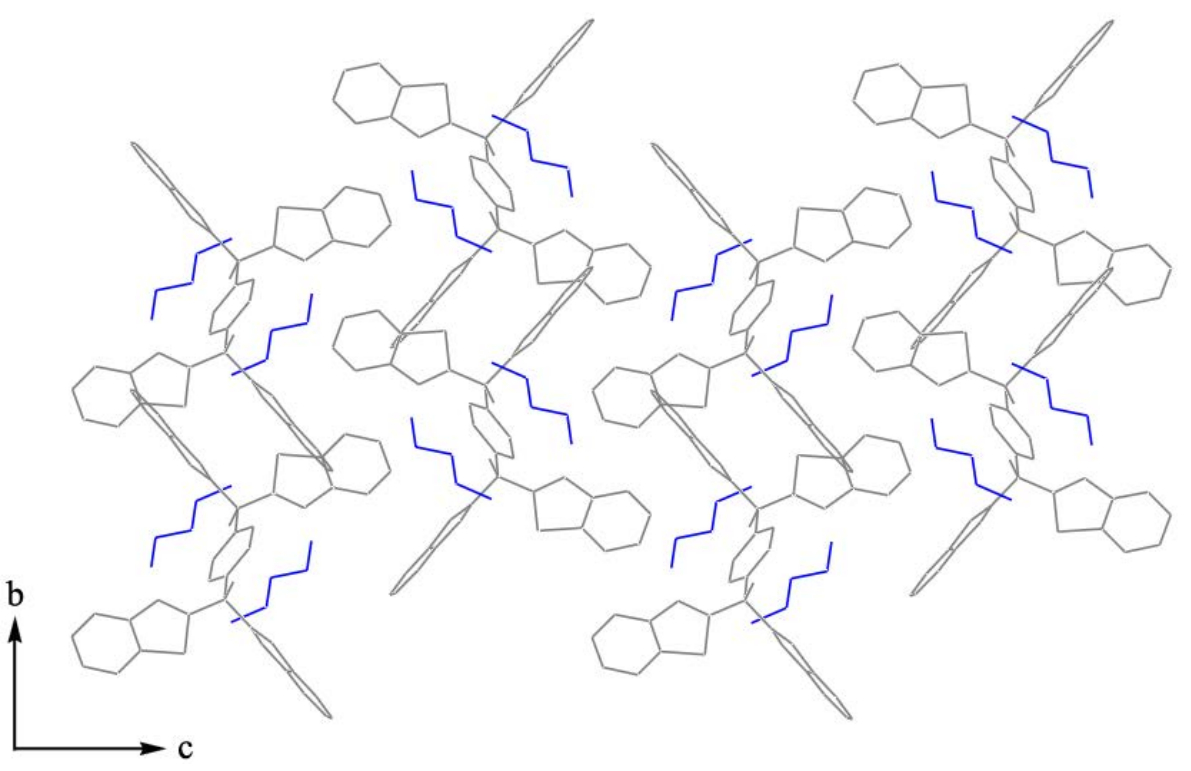


(b)

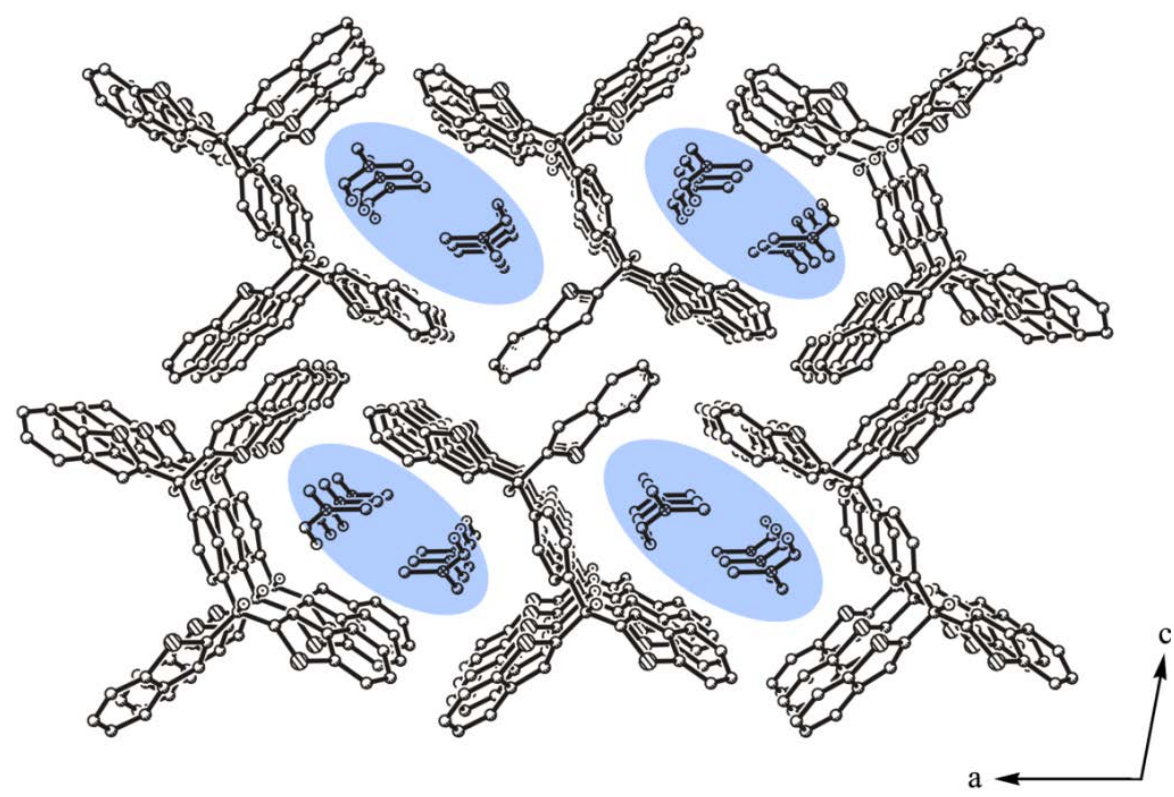

Figure 9. Packing structures of $\mathbf{4 a}$ (a) and $\mathbf{4 d}$ (b). In (a), the cage-like packing structure shows included acetone molecules while in (b) guest DMF molecules are accommodated in the channel framework of host $\mathbf{4}$. Non-relevant H-atoms have been omitted for clarity.

Relating to the cage inclusions $\mathbf{4 a}$ and $\mathbf{4 b}$ (Fig. 10a,b), the proton donating $\mathrm{Et}_{2} \mathrm{NH}$ and pyrrolidine guest molecules are involved in hydrogen bond ring motifs with the graph set $\mathrm{R}_{4}^{4}(8)$ including strong $\mathrm{O}-\mathrm{H} \cdots \mathrm{N}-$ and $\mathrm{N}-\mathrm{H} \cdots \mathrm{O}$-interactions [4a: $\mathrm{d}(\mathrm{O} 1 \cdots \mathrm{N} 1 \mathrm{G})=2.718(2) \AA$, $\mathrm{d}(\mathrm{N} 1 \mathrm{G} \cdots \mathrm{O} 1)=3.031(2) \AA ;$ 4b: $\mathrm{d}(\mathrm{O} 1 \cdots \mathrm{N} 1 \mathrm{G})=2.645(2) \AA, \mathrm{d}(\mathrm{N} 1 \mathrm{G} \cdots \mathrm{O} 1)=3.035(2) \AA]$ between host $\mathrm{OH}$ and guest $\mathrm{NH}$ groups. In the case of the pyrrolidine inclusion $\mathbf{4} \mathbf{b}$, additional $\mathrm{C}-\mathrm{H} \cdots \mathrm{S}$ - and $\mathrm{C}-\mathrm{H} \cdots \pi$-contacts assist the host-guest interaction. The acetone molecules in 4c (Fig. 10c) show conventional hydrogen bonding between guest carbonyl and host hydroxyl groups $[\mathrm{d}(\mathrm{O} 1 \cdots \mathrm{O} 1 \mathrm{G})=2.775(3) \AA]$ supported by $\mathrm{C}-\mathrm{H} \cdots \mathrm{S}$-contacts $[\mathrm{d}(\mathrm{C} 2 \mathrm{G} \cdots \mathrm{S} 2)=3.680(4)$ $\AA$, $d(C 2 G \cdots S 2)=3.200(4) \AA]$ embracing the guest moieties. The DMF guests included in the channels of 4d (Fig. 10d) are connected via a strong $\mathrm{O}-\mathrm{H} \cdots \mathrm{O}$-hydrogen bond to a host $\mathrm{OH}$ group $[\mathrm{d}(\mathrm{O} 1 \cdots \mathrm{O} 1 \mathrm{G})=2.724(2) \quad \AA]$ and take also part in a $\mathrm{C}-\mathrm{H} \cdots \pi$-interaction $[\mathrm{d}(\mathrm{C} 2 \cdots \mathrm{Cg} 6)=3.557(2) \AA]$. A special host-guest bonding situation is shown in the structure of 4e (Fig. 10e). Here, the 1,4-dioxane guest molecules, being twofold disordered ( $s o f=0.63$ ), are linked in cages of host molecules by strong $\mathrm{O}-\mathrm{H} \cdots$ O-hydrogen bonding to host $\mathrm{OH}$ groups $[\mathrm{d}(\mathrm{O} 1 \cdots \mathrm{O} 2 \mathrm{~GB})=2.783(5) \AA]$. In addition, $\mathrm{C}-\mathrm{H} \cdots \mathrm{O}$-interactions $[\mathrm{d}(\mathrm{C} 4 \cdots \mathrm{O} 2 \mathrm{G})=$ 3.493(4) $\AA$ ] assist the host-guest stabilization resulting in the formation of a hydrogen bond ring motif with the graph set $\mathrm{R}_{3}^{2}(13) .{ }^{29,30}$ Moreover, $\mathrm{C}-\mathrm{H} \cdots \pi$-interactions procure a further host-guest connection giving rise to a second hydrogen bond ring motif with the graph set 
$\mathrm{R}_{2}^{2}(6)$ resulting from weak $\mathrm{C}-\mathrm{H} \cdots \mathrm{O}$-hydrogen bonding contacts $[\mathrm{d}(\mathrm{C} 1 \mathrm{G} \cdots \mathrm{O} 1 \mathrm{G})=3.223(2)$ $\AA$ ] of neighboring 1,4-dioxane molecules.

(a)

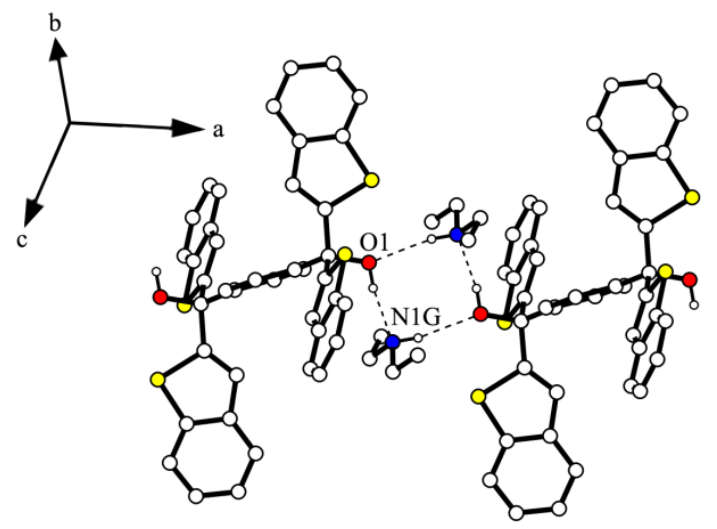

(b)

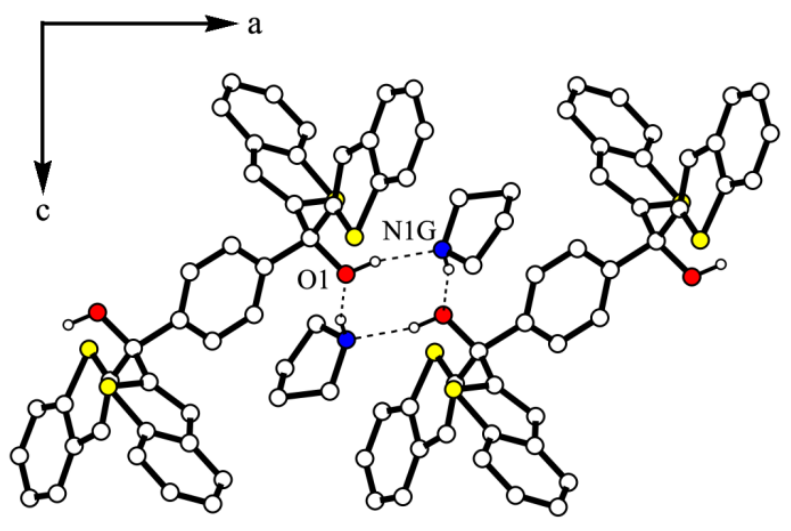

(c)

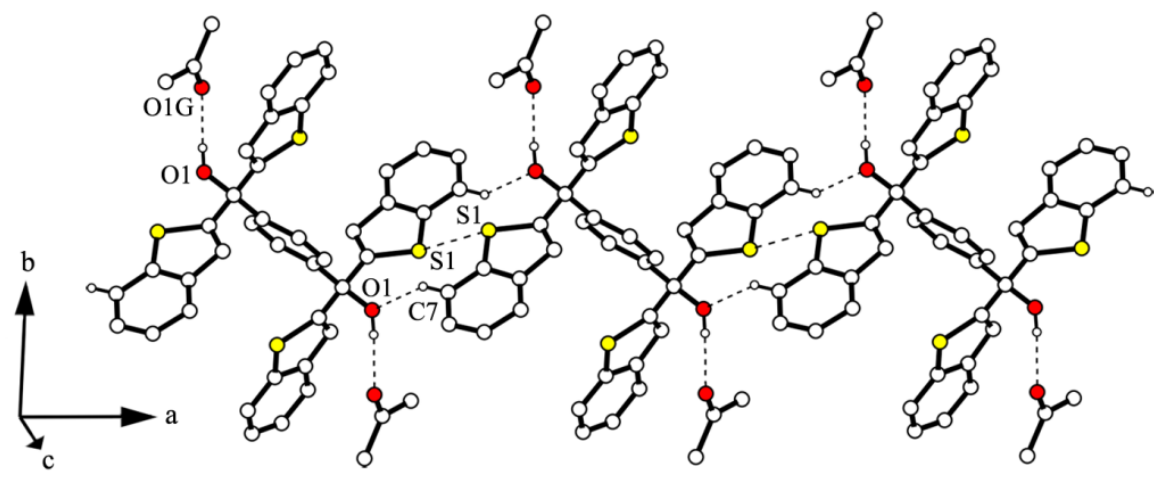

(d)

(e)
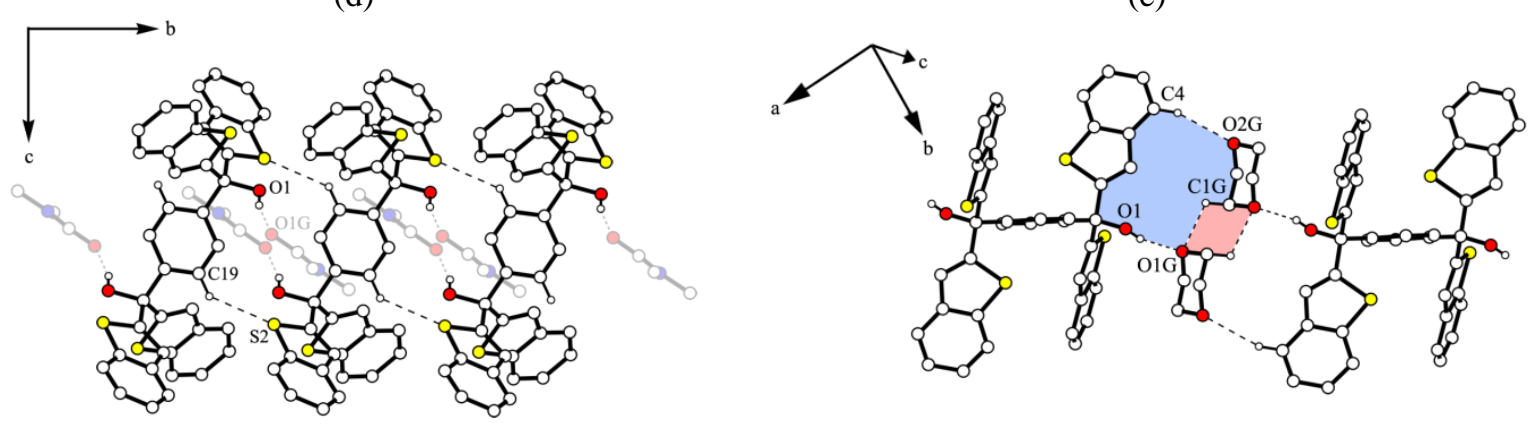

Figure 10. Packing excerpts illustrating details of intermolecular contact modes present in the crystal structures of $\mathbf{4 a - 4 e}$ (a-e, respectively). Non-relevant H-atoms have been omitted for clarity.

Sorption behavior. In order to further investigate the selectivity of guest accommodation, hosts $\mathbf{3}$ and $\mathbf{4}$ have been deposited as solid layers on a quartz crystal microbalance (QCM) ${ }^{20}$ instrument. To make possible a sound comparison with previous data obtained from 2, a 
series of different solvent vapors representing varied polarity properties with protic as well as aprotic characteristics but being in correspondence with a former selection of vapors ${ }^{17}$ has been used. Hence, the test substances include vapors of $n$-hexane, $\mathrm{CHCl}_{3}$, THF, acetone, $\mathrm{EtOH}$ and $\mathrm{Et}_{2} \mathrm{NH}$. Considering the sorption rates (Fig. 11), it becomes obvious that 3, in comparison with $\mathbf{4}$, features a higher activity of sorption for almost all used solvents which might be connected with the difference in dimensions of the central building units, ethynylene in 3 and 1,4-phenylene in $\mathbf{4}$, giving rise to different packing in the solid state. However, unlike $\mathbf{4}$, solvent-free crystals of $\mathbf{3}$ could not be isolated in a quality suitable for X-ray study to show details of the packing for making a sound reasoning based on an appropriate approach possible. Additionally, in the solid state a dynamic alteration of the solvent-free packing should be taken into account, ${ }^{35,36}$ whether or not depending on the provided guest molecule. All this makes it difficult to give a conclusive explanation for the different behavior of $\mathbf{3}$ and 4. Considering this kind of reservation, in a more detailed presentation, the results appear as follows. While 4 shows a similar sorption of THF, acetone, $\mathrm{EtOH}$ and $\mathrm{Et}_{2} \mathrm{NH}$ of ca. $40 \%, 3$ indicates high penchant for the sorption of $\mathrm{EtOH}$ in a ratio of $212 \%$ which equates nearly to 1:2 stoichiometry found in the solvent crystallization followed by $\mathrm{Et}_{2} \mathrm{NH}$ (116 \%, ca. 1:1), THF (80\%), $\mathrm{CHCl}_{3}(51 \%)$ and acetone (43\%). The high preference of 3 in the uptake of $\mathrm{EtOH}$ and $\mathrm{Et}_{2} \mathrm{NH}$ is attributed to their protic character, inducing strong hydrogen bonding between host and guest. Yet, since 3 shows almost twice the amount of $\mathrm{Et}_{2} \mathrm{NH}$ for $\mathrm{EtOH}$ in the sorption of vapor, we assume the smaller size of EtOH compared to $\mathrm{Et}_{2} \mathrm{NH}$ supplying an additional explanation.

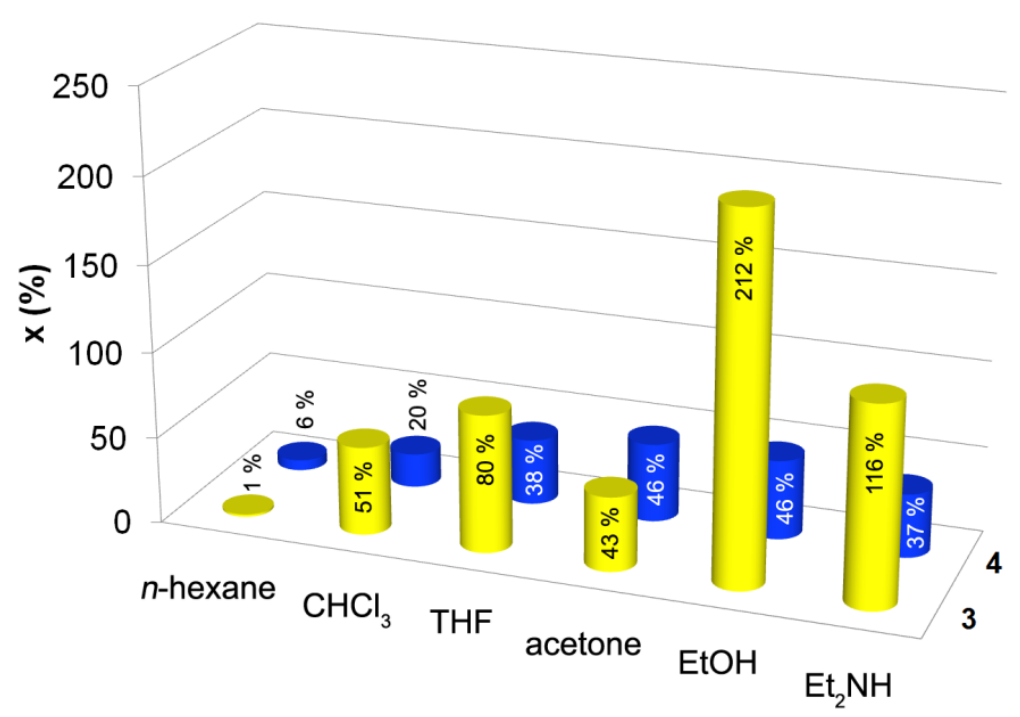

Figure 11. Absorption data from measurements of $\mathbf{3}$ and $\mathbf{4}$ with QCM comparing different solvent vapors. 


\section{CONCLUSION}

Carbonyl addition reactions of benzo[b]thien-2-yl-lithium to corresponding diesters successfully gave the new diol compounds $\mathbf{3}$ and $\mathbf{4}$ in respectable yields of 65 and 75\%, respectively. As expected, the replacement of 2-thienyl groups in $\mathbf{2}$ by the more bulky benzo[b]thien-2-yl moieties in $\mathbf{3}$ and $\mathbf{4}$ resulted in a distinctly increased capability of the inclusion of organic solvent molecules via solvent crystallization. This is particularly noticeable in the compound ranges of alcohols $(\mathrm{MeOH}, \mathrm{EtOH})$ and dipolar aprotic solvents (EtOAc, DMF, pyridine, THF) being only of minor importance in the inclusions of 2, whereas compared with toluene and chloroform $\mathbf{3}$ and $\mathbf{4}$ are remarkably alike $\mathbf{2}$ in the failure of inclusion. Another striking result is that the host : guest inclusion stoichiometry both of $\mathbf{3}$ and 4, only excepting for EtOAc, is generally found to be $1: 2$, clearly corresponding to the bifunctionality of the hosts. By contrast, 2 is much less uniform in this respect. ${ }^{17}$ As it seems, small differences in the length and space of the core units, either ethynylene or 1,4-phenylene in the molecular structures of $\mathbf{3}$ and $\mathbf{4}$ affect only the inclusion of alcohols.

The crystal structures of $\mathbf{3}$ and $\mathbf{4}$ uniformly indicate that the hydroxyl groups are not involved in intramolecular interactions but are engaged in the binding of the corresponding guests via $\mathrm{O}-\mathrm{H} \cdots \mathrm{O}$ or $\mathrm{O}-\mathrm{H} \cdots \mathrm{N}$ contacts and in one particular case, the solvent free crystal of 4, to neighboring diol molecules. Host-guest contacts of the conventional hydrogen bond type are supported according to the given opportunity by weaker $\mathrm{C}-\mathrm{H} \cdots \mathrm{O}$ or $\mathrm{C}-\mathrm{H} \cdots \pi$ and to a lesser extent also $\mathrm{C}-\mathrm{H} \cdots \mathrm{S}$ interactions, in some cases giving rise to the formation of hydrogen bonded ring systems. With reference to the topological relation between host and guest, channel-type inclusion is given priority to cage inclusion concerning the complexes of $\mathbf{3}$ while those of $\mathbf{4}$ are opposite preferring a cage topology although a strand-like connection of the host molecules is a general characteristic feature of the inclusion structures.

Sorption experiments applying a quartz crystal microbalance coated with solid films of $\mathbf{3}$ and $\mathbf{4}$ yielded distinctly different behavior pattern regarding the two compounds. Whereas $\mathbf{4}$ shows rather negligible uptake of the variety of apolar to polar solvents being used, $\mathbf{3}$ proved high efficient with selected solvent vapors. In particular, this applies to the polar protic $\mathrm{Et}_{2} \mathrm{NH}$ and more enhanced to EtOH compared with aprotic solvent species indicating a favorable interplay of the protic functions of host and guest in forming the sorptive complex. Combined with the sorption behavior previously found for $2,{ }^{17}$ this should offer a promising new possibility for sensor development. ${ }^{37}$ Nevertheless, the behavior pattern of $\mathbf{3}$ toward vapor of $\mathrm{EtOH}$ in comparison to crystallization from EtOH are not completely in coherence. But this 
shows once again that vapor sorption and solvent co-crystallization properties are only limited transferable. On the other side, the large difference in the sorptive efficiency found between 3 and $\mathbf{4}$ could be attributed to the geometric difference of the host molecules possibly promoting a more easily accessible host channel in the case of $\mathbf{3}$.

In summary, the results of this study show that with the benzo[b]thien-2-yl substituted compounds $\mathbf{3}$ and $\mathbf{4}$ a promising expansion of the coordinato-clathrate and wheel-and-axle strategies is available. This first members of an expected new versatile host family may open a new chapter of supramolecular inclusion formation ${ }^{8,12}$ with stimulation of manifold applications e.g. for sensors and actuators. ${ }^{20,37}$

\section{EXPERIMENTAL SECTION}

General Remarks. The melting points were measured on a microscope heating stage Thermovar (Reichert-Jung). IR spectra were recorded on a Nicolet FT-IR 510 spectrometer as $\mathrm{KBr}$ pellets (wave numbers given in $\mathrm{cm}^{-1}$ ). ${ }^{1} \mathrm{H}$ and ${ }^{13} \mathrm{C}$ NMR spectra were obtained from a Bruker Avance 500 at $500.1\left({ }^{1} \mathrm{H}\right)$ and $125.8 \mathrm{MHz}\left({ }^{13} \mathrm{C}\right)$ using TMS as internal standard. Chemical shifts for proton and carbon resonances are given in $\mathrm{ppm}(\delta)$. Signal multiplicity is characterized by s (singlet), d (doublet) and td (triplet split in doublets). Mass spectra were recorded on a Hewlett Packard 5890 Series II/MS 5971 A.

Materials. Solvents were purified by standard procedures. Starting compounds benzo[b]thiophene (97\%) and dimethyl acetylenedicarboxylate (98\%) were purchased from Acros Organics (Belgium) and dimethyl terephthalate (99 \%) from ABCR (Germany).

\section{Preparation of Compounds.}

General procedure. To a mixture of benzo[b]thiophene $(2.79 \mathrm{~g}, 20.8 \mathrm{mmol})$ in $20 \mathrm{ml}$ dry THF cooled to $-30{ }^{\circ} \mathrm{C}$ and under argon, $n$-BuLi (13.0 ml, $20.8 \mathrm{mmol}, 1.6 \mathrm{M}$ in $n$-hexane) was added slowly via syringe. After stirring the solution for $15 \mathrm{~min}$ at $-30{ }^{\circ} \mathrm{C}$, dimethyl acetylenedicarboxylate or dimethyl terephthalate $(4.2 \mathrm{mmol}$ ) dissolved in $20 \mathrm{ml}$ dry THF was added dropwise. The resulting mixture was stirred for $5 \mathrm{~h}$ at room temperature and then hydrolyzed with sat. aqueous $\mathrm{NH}_{4} \mathrm{Cl}$ solution. The organic phase was extracted three times with chloroform. The combined extracts have been dried $\left(\mathrm{Na}_{2} \mathrm{SO}_{4}\right)$ and evaporated. The residue was stirred in $50 \mathrm{ml} \mathrm{EtOH}$ for $20 \mathrm{~min}$ at $50{ }^{\circ} \mathrm{C}$ followed by hot filtration to yield the diol compound as a white solid. 
1,1,4,4-Tetra(benzo[b]thien-2-yl)but-2-yne-1,4-diol (1). Yield: 2.08 g, 65 \%. Mp > $240{ }^{\circ} \mathrm{C}$ (dec.). $\delta_{\mathrm{H}}\left(500.1 \mathrm{MHz}, \mathrm{DMSO}-\mathrm{d}_{6}, \mathrm{TMS}\right) 7.20(2 \mathrm{H}, \mathrm{s}, \mathrm{OH}), 7.36\left(8 \mathrm{H}, 2 \mathrm{td}, \mathrm{BThH}_{5 / 6}\right.$, $\left.J_{\mathrm{HH}}=7.10,1.50 \mathrm{~Hz}\right), 7.59\left(4 \mathrm{H}, \mathrm{s}, \mathrm{BThH}_{3}\right), 7.78\left(4 \mathrm{H}, \mathrm{d}, \mathrm{BThH}_{4}, J_{\mathrm{HH}}=6.85,1.95 \mathrm{~Hz}\right), 7.94$ $\left(4 \mathrm{H}, \mathrm{d}, \mathrm{BThH}_{7}, J_{\mathrm{HH}}=6.85,1.75 \mathrm{~Hz}\right) . \delta_{\mathrm{C}}\left(125.8 \mathrm{MHz}, \mathrm{CDCl}_{3}\right) 68.9(\mathrm{C}-\mathrm{OH}), 87.2(\mathrm{C} \equiv \mathrm{C})$, $121.3\left(\mathrm{BThC}_{3}\right), 122.5\left(\mathrm{BThC}_{7}\right), 124.0\left(\mathrm{BThC}_{4}\right), 124.5\left(\mathrm{BThC}_{5}\right), 124.7\left(\mathrm{BThC}_{6}\right), 138.7$ (BThC $\left.{ }_{3 a}\right), 139.2\left(\mathrm{BThC}_{7 \mathrm{a}}\right), 150.4\left(\mathrm{BThC}_{2}\right) \cdot v_{\max }(\mathrm{KBr}) / \mathrm{cm}^{-1} 3162(\mathrm{~m}, \mathrm{OH}), 3053\left(\mathrm{w}, \mathrm{CH}_{\mathrm{Ar}}\right)$, 1455, 1433 (m, OH), 1328, 1304 (w, C=C), 1043 (m, OH), 748 (s, CH); m/z: 637.0 [M+Na] . Found: C, 67.96; H, 4.85; S, 18.14; $\mathrm{C}_{40} \mathrm{H}_{26} \mathrm{O}_{2} \mathrm{~S}_{4} \cdot 2 \mathrm{EtOH}$ requires C, 68.10; H, 4.64; S, 17.95 $\%$.

1,4-Bis[di(benzo[b]thien-2-yl)hydroxymethyl]benzen (2). Yield: 2.14 g, 76 \%. Mp > $258{ }^{\circ} \mathrm{C}$ (dec.). $\delta_{\mathrm{H}}\left(500.1 \mathrm{MHz}, \mathrm{CDCl}_{3}, \mathrm{TMS}\right) 3.52(2 \mathrm{H}, \mathrm{s}, \mathrm{OH}), 7.15\left(4 \mathrm{H}, \mathrm{s}, \mathrm{BThH}_{3}\right), 7.32$ $\left(8 \mathrm{H}, 2 \mathrm{td}, \mathrm{BThH}_{5 / 6}, J_{\mathrm{HH}}=7.20,1.60 \mathrm{~Hz}\right), 7.59(4 \mathrm{H}, \mathrm{s}, \mathrm{Ph}), 7.68\left(4 \mathrm{H}, \mathrm{m}, \mathrm{BThH}_{4}\right), 7.78(4 \mathrm{H}, \mathrm{m}$, $\left.\mathrm{BThH}_{7}\right) . \quad \delta_{\mathrm{C}}\left(125.8 \mathrm{MHz}, \mathrm{CDCl}_{3}\right) 78.6(\mathrm{C}-\mathrm{OH}), 122.4\left(\mathrm{BThC}_{3}\right), 123.6\left(\mathrm{BThC}_{7}\right), 124.0$

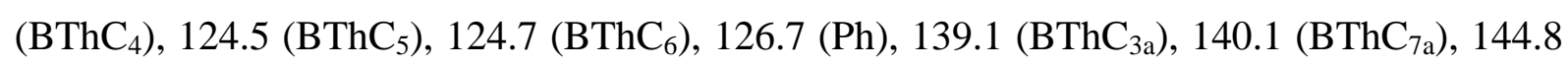
(Ph), $151.1\left(\mathrm{BThC}_{2}\right) \cdot v_{\max }(\mathrm{KBr}) / \mathrm{cm}^{-1}$ 3547, $3392(\mathrm{~m}, \mathrm{OH}), 3056,2971\left(\mathrm{w}, \mathrm{CH}_{\mathrm{Ar}}\right), 1461$, 1432 (m, OH), 1334, 1302 (w, C=C), 1090 (m, OH), 745 (s, CH); m/z: 664.9 [M-H]. Found: C, 71.38; H, 4.24; S, 18.59; $\mathrm{C}_{40} \mathrm{H}_{26} \mathrm{O}_{2} \mathrm{~S}_{4} \cdot 1 / 2 \mathrm{EtOH}$ requires C, 70.98; H, 4.38; S, $18.36 \%$.

X-ray Crystallography. The single crystal X-ray diffraction data of the studied compounds were collected at $100 \mathrm{~K}$ on a Bruker Kappa diffractometer equipped with an APEX II CCD area detector and graphite-monochromatized Mo K $\alpha$ radiation $(\lambda=0.71073 \AA)$ employing $\varphi$ and $\omega$ scan modes. The data were corrected for Lorentz and polarization effects. Semiempirical absorption correction was applied using the SADABS program. ${ }^{38}$ The SAINT program $^{38}$ was used for the integration of the diffraction profiles. The crystal structures were solved by direct methods using SHELXS-97 $7^{39}$ and refined by full-matrix least-squares refinement against $F^{2}$ using SHELXL-97. ${ }^{39}$ All non-hydrogen atoms were refined anisotropically. Hydrogen atoms were positioned geometrically and allowed to ride on their parent atoms. Geometrical calculations were performed using PLATON, ${ }^{40}$ and molecular graphics were generated using SHELXTL. ${ }^{39}$ In the crystal structures $\mathbf{3 b}, \mathbf{3 c}$ and $\mathbf{3 d}$, the solvent molecules could not be refined satisfactorily. Therefore they have been removed by the SQUEEZE method ${ }^{40}$ of the PLATON program and the structure refinement was completed without solvent molecules. Owing to the low residual electron density of $\mathbf{4 b}$, only the sulfur atom of the second disorder site could be found and was refined isotropic. 
The crystallographic data for the structures reported in this paper have been deposited with the Cambridge Crystallographic Data Center (CCDC) under http://ccdc.cam.ac.uk. CCDC deposition numbers: 1408792 (3a), 1408793 (3b), 1408794 (3c), 1408795 (3d), 1408796 (3e), 1408797 (3f), 1408798 (4), 1408799 (4a), 1408800 (4b), 1408801 (4c), 1408802 (4d), 1408803 (4e).

Absorption measurements. For the absorption experiments, a quartz crystal microbalance consisting of two electronic quartzes $(10 \mathrm{MHz})$ with gold electrodes (FOQ Piezo Technik, Germany) was used. The reference quartz is uncoated while the other quartz is coated with the respective diol host. The measurements were carried out at constant temperature $\left(25^{\circ} \mathrm{C}\right)$ and with a constant flow of synthetic air $(10 \mathrm{~L} / \mathrm{h})$. A multichannel frequency counter (HKR sensor systems Munich, Germany) with a resolution of $1 \mathrm{~Hz}$ was used to measure the resonance frequencies of the quartzes which can be read by a computer using a serial interface. The coating of the quartz was done by dipping in a $0.01 \mathrm{M}$ solution of the respective diol compound in $\mathrm{CHCl}_{3}$. The change of the frequency is proportional to the increase of the quartz mass induced by the sorption of the added solvent vapor. This relation results from the Sauerbrey equation. ${ }^{41}$ In consideration of the molar mass of the used solvents, the percentage of the adsorbed solvent can be obtained as molar ratio.

\section{ASSOCIATED CONTENT}

\section{Supporting Information}

Additional packing diagrams for compounds 3a, 3c, 3d, 3f and $\mathbf{4 b - 4 e . ~ T h e ~ S u p p o r t i n g ~}$ Information is available free of charge via the Internet at DOI....

\section{AUTHOR INFORMATION}

\section{Corresponding Authors}

*E-mail: edwin.weber@chemie.tu-freiberg.de; tobias.gruber@chemie.tu-freiberg.de

\section{Notes}

The authors declare no competing financial interest.

\section{ACKNOWLEDGEMENTS}

Financial support by the European Union (European regional development fund) and by the Ministry of Science and Art of Saxony (Cluster of Excellence "Structure Design of Novel 
High-Performance Materials via Atomic Design and Defect Engineering [ADDE]") is gratefully acknowledged by FK and EW.

\section{REFERENCES}

(1) Vittal, J.J.; Zaworotko, M.; Tieking; E. R. T.; Eds. Organic Crystal Engineering; Wiley: New York, 2010.

(2) Desiraju, G. R. Angew. Chem., Int. Ed. 2007, 46, 8342-8356.

(3) Braga, D.; Creponi, F., Eds. Making Crystals by Design: Methods, Techniques and Applications; Wiley-VCH: Weinheim, Germany, 2007.

(4) MacNicol, D. D.; Toda, F.; Bishop, R., Eds. Comprehensive Supramolecular Chemistry; Elsevier: Oxford, U.K., 1996; vol. 6.

(5) Hertzsch, T.; Hulliger, J.; Weber, E.; Sozzani, P. In Encyclopedia of Supramolecular Chemistry; Atwood, J. L.; Steed, J. W. Eds.; CRC Press: Boca Raton, FL, 2004; pp 996-1005.

(6) Toda, F., Ed. Organic Solid State Reactions; Topics in Current Chemistry; SpringerVerlag: Berlin-Heidelberg, 2005; Vol. 254.

(7) Gillivray, L. R., Ed. Metal-Organic Frameworks: Design and Application; Wiley: Hoboken, NY, 2010.

(8) Weber, E. In Inclusion Compounds; Atwood, J. L., Davies, J. E. D.; MacNicol, D. D., Eds.; Oxford University Press: Oxford, U.K., 1991; vol. 4, pp 188-262.

(9) Weber, E.; Czugler, M. In Molecular Inclusion and Molecular Recognition: Clathrates II; Weber, E., Ed.; Topics in Current Chemistry; Springer-Verlag: BerlinHeidelberg, 1988; Vol. 149, pp 45-135.

(10) Toda, F. In Comprehensive Supramolecular Chemistry; MacNicol, D. D., Toda, F., Bishop, R., Eds.; Elsevier: Oxford, U.K., 1996; vol. 6., pp 465-516.

(11) Hart, H.; Lin, L.-T.-W; Ward, D. L. J. Am. Chem. Soc. 1984, 106, 4043-4045.

(12) Weber, E. In Comprehensive Supramolecular Chemistry; MacNicol, D. D., Toda, F., Bishop, R., Eds.; Elsevier: Oxford, U.K., 1996; vol. 6., pp 535-592.

(13) Klien, H.; Seichter, W.; Weber, E. CrystEngComm 2013, 15, 586-596.

(14) Klien, H.; Seichter, W.; Weber, E. Cryst. Growth Des. 2014, 14, 4371-4382.

(15) Bourne, S. A.; Nassimbeni, L. R.; Niven, M. L.; Weber, E.; Wierig, A. J. Chem. Soc., Perkin Trans. 2, 1994, 1215-1222.

(16) Weber, E.; Nitsche, S.; Wierig, A.; Csöregh, I. Eur. J. Org. Chem. 2002, 856-872.

(17) Katzsch, F.; Weber, E. CrystEngComm 2015, 17, 2737-2753. 
(18) Toda, F.; Kai, A.; Toyotaka, R.; Yip, W.-H.; Mak, T. C. W. Chem. Lett. 1989, 19211924.

(19) Weber, E.; Skobridis, K.; Wierig, A.; Nassimbeni, L. R. J. Chem. Soc., Perkin Trans 2, 1992, 2123-2130.

(20) Steinem, A. J. C.; Janshoff, A., Eds. Piezoelectric Sensors; Springer-Verlag: Heidelberg, 2006.

(21) Clark, R. D.; Jahangir, A. Lateral Lithiation Reactions Promoted by Heteroatomic Substituents. Organic Reactions 2004, 47, 1-314.

(22) Kucsman, A.; Kapovits, I.; Czugler, M.; Parkanyi, L.; Kalman, A. J Mol. Struct. 1989, 198, 339-353.

(23) Gleiter, R.; Werz, D. B.; Rausch, B. J. Chem. Eur. J. 2003, 9, 2676-2683.

(24) Long, D.-L.; Kögerler, P.; Cronin, L. Angew. Chem., Int. Ed. 2004, 43, 1817-1820.

(25) Novoa, J. J.; Rovira, M. C.; Rovira, C.; Veciana, J.; Tarrés, J. Adv. Mater. 1995, 7, 233-237.

(26) Kitaigorodskii, A. I. Molecular Crystals and Molecules; Academic Press: New York, 1973.

(27) James, S. L. In Encyclopedia of Supramolecular Chemistry; Atwood, J. L., Steed, J. W., Eds.; CRC Press: Boca Raton, FL, 2004; pp 1093-1099.

(28) Martinez, C. R.; Iverson, B. L. Chem. Sci. 2012, 3, 2191-2201.

(29) Etter, M. C. J. Phys. Chem. 1991, 95, 4601-4610.

(30) Bernstein, J.; Davies, R. E.; Shimoni, L.; Chang, N.-L. Angew. Chem., Int. Ed. 1995, 34, 1555-1573.

(31) Desiraju, G. R., Steiner, T. The Weak Hydrogen Bond in Chemistry and Structural Biology; IUCR Monographs on Crystallography; Oxford University Press: Oxford, 1999; Vol. 9, pp $29-121$.

(32) Nishio, M., Umezawa, Y., Suezawa, H., Tsuboyama, S. In The Importance of PiInteractions in Crystal Engineering; Tiekink, E. R. T., Zukerman-Schpector, J., Eds.; Wiley: Chichester, 2012; pp 1 - 39.

(33) Nishio, M.; Umezawa, Y.; Honda, K.; Tsuboyama, S.; Suezawa, H. CrystEngComm 2009, 11, 1757-1788.

(34) Desiraju, G. R., Steiner, T. The Weak Hydrogen Bond in Chemistry and Structural Biology; IUCR Monographs on Crystallography; Oxford University Press: Oxford, 1999; Vol. 9, pp 122-201. 
(35) Reinbold, J.; Buhlmann, K.; Cammann, K.; Wierig, A.; Wimmer, C.; Weber., E. Sens. Actuators B, 1994, 18/19, 77-81.

(36) Schindler, D.; Eißmann, F.; Weber, E. Org. Biomol. Chem. 2009, 7, 3549-3560.

(37) Arnau, A., Ed. Piezoelectric Transducers and Applications; Springer-Verlag: Heidelberg, 2004.

(38) SAINT, SADABS, Bruker AXS Inc.; Madison, WI, USA, 2008.

(39) Sheldrick, G. M. Acta Cryst. 2008, A64, 112-122.

(40) Spek, L. Acta Crystallogr. 2009, D65, 148-155.

(41) Sauerbrey, G. Z. Phys.1959, 155, 206-222. 
TABLES

Table 1. Crystalline Inclusion

Compounds Formed of the

Diol Hosts 3 and 4 (including

$2^{17}$ for purpose of comparison

\begin{tabular}{lccc}
\hline Solvents & $\mathbf{2}$ & $\mathbf{3}$ & $\mathbf{4}$ \\
\hline MeOH & - & $1: 2$ & $\boldsymbol{c}$ \\
EtOH & - & $\boldsymbol{c}$ & $1: 2$ \\
$n$-PrOH & $1: 2$ & $1: 2$ & - \\
$n$-BuOH & $1: 2$ & $1: 2$ & - \\
diethylamine & - & $1: 2$ & $1: 2$ \\
pyrrolidine & $1: 2$ & $1: 2$ & $1: 2$ \\
acetone & $2: 1$ & $1: 2$ & $1: 2$ \\
EtOAc & $c$ & $1: 1$ & $3: 2$ \\
DMSO & $2: 1$ & $1: 2$ & $1: 2$ \\
DMF & - & $1: 2$ & $1: 2$ \\
pyridine & $c$ & $1: 2$ & $1: 2$ \\
THF & $c$ & $1: 2$ & $1: 2$ \\
1,4-dioxane & $1: 1$ & $1: 2$ & $1: 2$ \\
toluene & - & - & - \\
chloroform & - & - & - \\
\hline c...difficult to crystallize. &
\end{tabular}


Table 2. Crystallographic Data and Structure Refinement Details of the Compounds Studied

\begin{tabular}{|c|c|c|c|c|c|c|}
\hline & 3a & $\mathbf{3 b}$ & $3 c$ & 3d & 3e & $3 f$ \\
\hline empirical formula & $\mathrm{C}_{36} \mathrm{H}_{22} \mathrm{O}_{2} \mathrm{~S}_{4} \cdot 2 \mathrm{C}_{4} \mathrm{H}_{10} \mathrm{O}$ & $\mathrm{C}_{36} \mathrm{H}_{22} \mathrm{O}_{2} \mathrm{~S}_{4} \cdot 2 \mathrm{C}_{4} \mathrm{H}_{9} \mathrm{~N}$ & $\mathrm{C}_{36} \mathrm{H}_{22} \mathrm{O}_{2} \mathrm{~S}_{4} \cdot 2 \mathrm{C}_{3} \mathrm{H}_{6} \mathrm{O}$ & $\mathrm{C}_{36} \mathrm{H}_{22} \mathrm{O}_{2} \mathrm{~S}_{4} \cdot 2 \mathrm{C}_{2} \mathrm{H}_{6} \mathrm{OS}$ & $\mathrm{C}_{36} \mathrm{H}_{22} \mathrm{O}_{2} \mathrm{~S}_{4} \cdot 2 \mathrm{C}_{3} \mathrm{H}_{7} \mathrm{NO}$ & $\mathrm{C}_{36} \mathrm{H}_{22} \mathrm{O}_{2} \mathrm{~S}_{4} \cdot 2 \mathrm{C}_{4} \mathrm{H}_{8} \mathrm{O}$ \\
\hline formula weight & 763.02 & 614.82 & 614.82 & 614.82 & 760.97 & 759.02 \\
\hline crystal system & monoclinic & monoclinic & monoclinic & monoclinic & monoclinic & triclinic \\
\hline space group & $P 2_{1} / n$ & $P 2_{1} / n$ & $P 2_{1} / n$ & $P 2_{1} / n$ & $P 2_{1} / c$ & $P-1$ \\
\hline$a(\AA)$ & $12.5432(6)$ & $10.3085(4)$ & $10.0685(3)$ & 10.1001(3) & $13.8602(4)$ & $8.3313(2)$ \\
\hline$b(\AA)$ & $6.0919(2)$ & $8.6898(3)$ & $8.4189(3)$ & $8.4594(2)$ & $13.4898(4)$ & $10.0446(3)$ \\
\hline$c(\AA)$ & 25.1916(11) & 23.6723(10) & 23.9505(8) & 23.9058(6) & $20.8830(5)$ & 12.0894(3) \\
\hline$\alpha\left(^{\circ}\right)$ & 90.0 & 90.0 & 90.0 & 90.0 & 90.0 & 68.703(2) \\
\hline$\beta\left(^{\circ}\right)$ & $103.126(2)$ & $99.378(2)$ & 98.9820(10) & 98.6950(10) & $102.7070(10)$ & $76.808(2)$ \\
\hline$\gamma\left({ }^{\circ}\right)$ & 90.0 & 90.0 & 90.0 & 90.0 & 90.0 & $87.818(2)$ \\
\hline$V\left(\AA^{3}\right)$ & 1874.65(14) & 2092.19(14) & 2005.29(11) & 2019.06(9) & 3808.89(18) & 916.61(4) \\
\hline$Z$ & 2 & 2 & 4 & 2 & 2 & 1 \\
\hline$F(000)$ & 804 & 636 & 636 & 636 & 1592 & 398 \\
\hline$D_{\mathrm{c}}\left(\mathrm{Mg} \mathrm{m}^{-3}\right)$ & 1.352 & 0.976 & 1.018 & 1.011 & 1.327 & 1.375 \\
\hline$\mu\left(\mathrm{mm}^{-1}\right)$ & 0.298 & 0.251 & 0.261 & 0.260 & 0.294 & 0.304 \\
\hline \multicolumn{7}{|l|}{ data collection } \\
\hline temperature (K) & $100(2)$ & $100(2)$ & $100(2)$ & $100(2)$ & $100(2)$ & $100(2)$ \\
\hline no. of collected reflections & 14063 & 15708 & 16221 & 19101 & 33129 & 15637 \\
\hline within the $\theta$-limit $\left(^{\circ}\right)$ & $1.69-25.00$ & $1.74-25.00$ & $1.72-25.00$ & $1.72-25.00$ & $1.81-25.00$ & $2.29-27.50$ \\
\hline index ranges $\pm h, \pm k, \pm l$ & $-14 / 14,-7 / 7,-29 / 26$ & $-12 / 12,-10 / 10,-28 / 28$ & $-11 / 11,-10 / 7,-28 / 28$ & $-1212,-10 / 8,-28 / 28$ & $-16 / 13,-15 / 16,-22 / 24$ & $-10 / 10,-13 / 13,-15 / 15$ \\
\hline no. of unique reflections & 3288 & 3678 & 3519 & 3541 & 6700 & 4195 \\
\hline$R_{\text {int }}$ & 0.0387 & 0.0299 & 0.0255 & 0.0236 & 0.0343 & 0.0266 \\
\hline weighting expression $w^{a}$ & $\begin{array}{l}{\left[\sigma^{2}\left(F_{o}^{2}\right)+(0.0432 P)^{2}+\right.} \\
0.9853 P]^{-1}\end{array}$ & $\begin{array}{l}{\left[\sigma^{2}\left(F_{\mathrm{o}}{ }^{2}\right)+(0.0827 P)^{2}+\right.} \\
1.1059 P]^{-1}\end{array}$ & $\begin{array}{l}{\left[\sigma^{2}\left(F_{o}^{2}\right)+(0.0639 P)^{2}+\right.} \\
10.3258 P]^{-1}\end{array}$ & $\begin{array}{l}{\left[\sigma^{2}\left(F_{o}^{2}\right)+(0.0412 P)^{2}+\right.} \\
1.6297 P]^{-1}\end{array}$ & $\begin{array}{l}{\left[\sigma^{2}\left(F_{o}^{2}\right)+(0.0480 P)^{2}+\right.} \\
4.5856 P]^{-1}\end{array}$ & $\begin{array}{l}{\left[\sigma^{2}\left(F_{o}^{2}\right)+(0.0246 P)^{2}+\right.} \\
0.6539 P]^{-1}\end{array}$ \\
\hline no. of refined parameters & 257 & 191 & 191 & 210 & 469 & 255 \\
\hline no. of F values used $[I>2 \sigma(I)]$ & 2542 & 3086 & 3223 & 3272 & 5696 & 3622 \\
\hline \multicolumn{7}{|l|}{ final $R$-Indices } \\
\hline$R\left(=\Sigma|\Delta F| / \Sigma\left|F_{\mathrm{o}}\right|\right)$ & 0.0385 & 0.0466 & 0.0740 & 0.0376 & 0.0437 & 0.0378 \\
\hline$w R$ on $F^{2}$ & 0.0899 & 0.1322 & 0.1894 & 0.0959 & 0.1080 & 0.0821 \\
\hline$S$ (=goodness of fit on $F^{2}$ ) & 1.056 & 1.053 & 1.090 & 1.048 & 1.084 & 1.088 \\
\hline final $\Delta \rho_{\max } / \Delta \rho_{\min }\left(\right.$ e $\left.\AA^{-3}\right)$ & $0.445 /-0.313$ & $0.432 /-0.388$ & $0.433 /-0.428$ & $0.295 /-0.408$ & $1.069 /-1.130$ & $0.319 /-0.270$ \\
\hline
\end{tabular}

${ }^{\mathrm{a}} \mathrm{P}=\left({F_{\mathrm{o}}}^{2}+2 F_{\mathrm{c}}{ }^{2}\right) / 3$.

Table 2. Continued 


\begin{tabular}{|c|c|c|c|c|c|c|}
\hline & 4 & $4 a$ & $4 b$ & $4 c$ & $4 d$ & $4 e$ \\
\hline empirical formula & $\mathrm{C}_{40} \mathrm{H}_{26} \mathrm{O}_{2} \mathrm{~S}_{4}$ & $\mathrm{C}_{40} \mathrm{H}_{26} \mathrm{O}_{2} \mathrm{~S}_{4} \cdot 2 \mathrm{C}_{4} \mathrm{H}_{11} \mathrm{~N}$ & $\mathrm{C}_{40} \mathrm{H}_{26} \mathrm{O}_{2} \mathrm{~S}_{4} \cdot 2 \mathrm{C}_{4} \mathrm{H}_{9} \mathrm{~N}$ & $\mathrm{C}_{40} \mathrm{H}_{26} \mathrm{O}_{2} \mathrm{~S}_{4} \cdot 2 \mathrm{C}_{3} \mathrm{H}_{6} \mathrm{O}$ & $\mathrm{C}_{40} \mathrm{H}_{26} \mathrm{O}_{2} \mathrm{~S}_{4} \cdot 2 \mathrm{C}_{3} \mathrm{H}_{7} \mathrm{NO}$ & $\mathrm{C}_{40} \mathrm{H}_{26} \mathrm{O}_{2} \mathrm{~S}_{4} \cdot 2 \mathrm{C}_{4} \mathrm{H}_{8} \mathrm{O}_{2}$ \\
\hline formula weight & 666.85 & 813.16 & 809.20 & 783.00 & 813.04 & 843.10 \\
\hline crystal system & triclinic & monoclinic & triclinic & monoclinic & monoclinic & monoclinic \\
\hline space group & $P-1$ & $P 2_{1} / n$ & $P-1$ & $P 2_{1} / c$ & $P 2_{1} / c$ & $P 2_{1} / \mathrm{c}$ \\
\hline$a(\AA)$ & $10.2865(2)$ & $10.5048(5)$ & $9.8871(3)$ & $10.8926(2)$ & 12.2921(3) & $12.3347(5)$ \\
\hline$b(\AA)$ & $11.2102(3)$ & $9.6623(4)$ & $10.0446(3)$ & $9.8674(2)$ & $6.46110(10)$ & 8.9162(3) \\
\hline$c(\AA)$ & $14.1646(3)$ & 20.7737(8) & $12.0267(3)$ & $17.8703(4)$ & $25.1260(6)$ & $18.2149(7)$ \\
\hline$\alpha\left(^{\circ}\right)$ & $110.2970(10)$ & 90.0 & 72.7070(10) & 90.0 & 90.0 & 90.0 \\
\hline$\beta\left(^{\circ}\right)$ & $91.0490(10)$ & $100.769(2)$ & $85.3700(10)$ & $93.3770(10)$ & $96.9240(10)$ & $92.373(2)$ \\
\hline$\gamma\left({ }^{\circ}\right)$ & $97.3960(10)$ & 90.0 & $64.5660(10)$ & 90.0 & 90.0 & 90.0 \\
\hline$V\left(\AA^{3}\right)$ & $1515.72(6)$ & 2071.41(15) & $1028.35(5)$ & 1917.39(7) & 1980.97(7) & 2001.53(13) \\
\hline$Z$ & 2 & 2 & 1 & 2 & 2 & 2 \\
\hline$F(000)$ & 692 & 860 & 426 & 820 & 852 & 884 \\
\hline$D_{\mathrm{c}}\left(\mathrm{Mg} \mathrm{m}^{-3}\right)$ & 1.461 & 1.304 & 1.306 & 1.356 & 1.363 & 1.399 \\
\hline$\mu\left(\mathrm{mm}^{-1}\right)$ & 0.352 & 0.272 & 0.273 & 0.293 & 0.288 & 0.290 \\
\hline \multicolumn{7}{|l|}{ data collection } \\
\hline temperature (K) & $100(2)$ & $100(2)$ & $100(2)$ & $100(2)$ & $100(2)$ & $100(2)$ \\
\hline no. of collected reflections & 30227 & 19438 & 20718 & 19451 & 25912 & 16425 \\
\hline within the $\theta$-limit $\left(^{\circ}\right)$ & $1.54-25.00$ & $2.89-28.39$ & $2.28-25.00$ & $2.28-25.00$ & $1.63-25.00$ & $2.54-26.00$ \\
\hline index ranges $\pm h, \pm k, \pm l$ & $-12 / 12,-13 / 13,-16 / 16$ & $-14 / 13,-12 / 12,-27 / 27$ & $-11 / 11,-11 / 11,-14 / 14$ & $-12 / 12,-11 / 11,-21 / 21$ & $-14 / 14,-7 / 5,-29 / 29$ & $-15 / 15,-10 / 10,-22 / 22$ \\
\hline no. of unique reflections & 5344 & 5148 & 3614 & 3379 & 3494 & 3929 \\
\hline \multicolumn{7}{|c|}{$\begin{array}{l}\text { refinement calculations: full-matrix least- } \\
\text { squares on all } F^{2} \text { values }\end{array}$} \\
\hline Weighting expression $w^{\mathrm{a}}$ & $\begin{array}{l}{\left[\sigma^{2}\left(F_{o}^{2}\right)+(0.0453 P)^{2}+\right.} \\
1.0655 P]^{-1}\end{array}$ & $\begin{array}{l}{\left[\sigma^{2}\left(F_{\mathrm{o}}^{2}\right)+(0.0446 P)^{2}+\right.} \\
0.7831 P]^{-1}\end{array}$ & $\begin{array}{l}{\left[\sigma^{2}\left(F_{o}^{2}\right)+(0.0246 P)^{2}+\right.} \\
0.6539 P]^{-1}\end{array}$ & $\begin{array}{l}{\left[\sigma^{2}\left(F_{0}^{2}\right)+(0.0523 P)^{2}+\right.} \\
5.1412 P]^{-1}\end{array}$ & $\begin{array}{l}{\left[\sigma^{2}\left(F_{\mathrm{o}}^{2}\right)+(0.0449 P)^{2}+\right.} \\
1.2381 P]^{-1}\end{array}$ & $\begin{array}{l}{\left[\sigma^{2}\left(F_{\mathrm{o}}^{2}\right)+(0.0647 P)^{2}+\right.} \\
0.7228 P]^{-1}\end{array}$ \\
\hline no. of refined parameters & 417 & 279 & 268 & 230 & 256 & 326 \\
\hline $\begin{array}{l}\text { no. of } \mathrm{F} \text { values used }[I>2 \sigma(I)] \\
\text { final } R \text {-Indices }\end{array}$ & 4731 & 3515 & 3338 & 3073 & 2969 & 3004 \\
\hline$R\left(=\Sigma|\Delta F| / \Sigma\left|F_{\mathrm{o}}\right|\right)$ & 0.0328 & 0.0470 & 0.0379 & 0.0564 & 0.0325 & 0.0469 \\
\hline$w R$ on $F^{2}$ & 0.0868 & 0.0962 & 0.0983 & 0.1358 & 0.0859 & 0.1179 \\
\hline$S$ (=goodness of fit on $F^{2}$ ) & 1.062 & 1.015 & 1.043 & 1.059 & 1.059 & 1.077 \\
\hline final $\Delta \rho_{\max } / \Delta \rho_{\min }\left(\mathrm{e} \AA^{-3}\right)$ & $0.686 /-0.371$ & $0.444 /-0.390$ & $0.744 /-0.303$ & $1.427 /-1.008$ & $0.388 /-0.336$ & $0.926 /-0.588$ \\
\hline
\end{tabular}

a $P=\left(F_{\mathrm{o}}{ }^{2}+2 F_{\mathrm{c}}^{2}\right) / 3$. 
Table 3. Selected Torsion Angles of the Host Conformations in the Crystal Structures of 3 and 4

\begin{tabular}{lcccccc}
\hline torsion angles (deg) & 3a & 3b & 3c & 3d & 3e & 3f \\
\hline$\tau 1$ (S1-C1-C17-O1) & $31.5(2)$ & $35.6(2)$ & $40.0(4)$ & $40.4(2)$ & $44.4(2)$ & $-38.3(2)$ \\
$\tau 2$ (S2-C9-C17-O1) & $-34.0(2)$ & $-38.3(2)$ & $-37.8(4)$ & $-36.7(2)$ & $32.6(2)$ & $-33.9(2)$ \\
$\tau 3$ (S3-C21-C20-O2) & & & & & $-41.4(2)$ & \\
$\tau 4$ (S4-C29-C20-O2) & & & & & $-32.9(2)$ & \\
\hline & $\mathbf{4}$ & $\mathbf{4 a}$ & $\mathbf{4 b}$ & $\mathbf{4 c}$ & $\mathbf{4 d}$ & $\mathbf{4 e}$ \\
\hline$\tau 1$ (S1-C1-C17-O1) & $50.4(2)$ & $-82.6(2)$ & $22.0(2)$ & $-10.3(3)$ & $47.5(2)$ & $-162.1(1)$ \\
$\tau 2$ (S2-C9-C17-O1) & $-166.5(1)$ & $25.3(2)$ & $58.7(2)$ & $81.9(2)$ & $29.8(2)$ & $-100.0(2)$ \\
$\tau 3$ (C20-C18-C17-O1) & $35.5(2)$ & $27.4(2)$ & $25.8(2)$ & $12.8(3)$ & $2.6(2)$ & $19.1(2)$ \\
$\tau 4$ (S3-C21-C37-O2) & $24.5(2)$ & & & & & \\
$\tau 5$ (S4-C29-C37-O2) & $44.7(2)$ & & & & & \\
$\tau 6$ (C40-C38-C37-O2) & $37.3(2)$ & & & & & \\
\hline
\end{tabular}

Table 4. Packing Properties of the Studied Inclusion Compounds

\begin{tabular}{cccccc}
\hline \multirow{2}{*}{ SAV $\left(\AA^{3}\right)$} & part of unit cell (\%) & \multicolumn{4}{c}{ KPI (\%) } \\
\cline { 4 - 5 } & & & without solvent & with solvent & \\
\hline 3a & 531.2 & 28.3 & 53.3 & 70.2 & ca $6.3 \times 9.8$ \\
3b & 726.2 & 36.0 & 49.2 & - & ca $6.2 \times 7.3$ \\
3c & 717.1 & 35.8 & 49.6 & - & ca $6.2 \times 7.2$ \\
3d & 792.2 & 37.9 & 47.5 & - & ca $6.4 \times 7.3$ \\
3e & 1067.9 & 28.0 & 52.3 & 67.2 & - \\
3f & 260.2 & 28.4 & 54.7 & 70.4 & - \\
4a & 613.6 & 29.6 & 52.9 & 68.9 & - \\
4b & 296.7 & 28.9 & 53.0 & 67.3 & - \\
4c & 489.8 & 25.5 & 57.0 & 69.5 & - \\
4d & 554.7 & 28.0 & 54.8 & 69.2 & ca $6.0 \times 11.7$ \\
4e & 529.2 & 26.4 & 55.2 & 71.2 & - \\
\hline
\end{tabular}

SAV...solvent accessible void, KPI...Kitaigorodskii packing index. 
Table 5. Non-covalent Interactions in the Crystal Structures Involving 3

\begin{tabular}{|c|c|c|c|c|}
\hline \multirow{2}{*}{ atoms involved } & \multirow{2}{*}{ symmetry } & \multicolumn{2}{|c|}{ distance $(\AA)$} & \multirow{2}{*}{$\begin{array}{l}\text { angle (deg) } \\
\text { D-H } \cdots \text { A }\end{array}$} \\
\hline & & $\mathrm{D} \cdots \mathrm{A}$ & $\mathrm{H} \cdots \mathrm{A}$ & \\
\hline \multicolumn{5}{|l|}{ За } \\
\hline $\mathrm{O} 1-\mathrm{H} 1 \cdots \mathrm{O} 1 \mathrm{G}$ & $2-x, 1-y, 1-z$ & $2.676(2)$ & 1.84 & 176.9 \\
\hline $\mathrm{C} 5-\mathrm{H} 5 \cdots \mathrm{S} 2$ & $1-x, 2-y,-z$ & $3.657(2)$ & 2.93 & 134.1 \\
\hline $\mathrm{C} 7-\mathrm{H} 7 \cdots \mathrm{S} 1$ & $1-x, 1-y,-z$ & $3.809(3)$ & 2.97 & 147.8 \\
\hline $\mathrm{C} 10-\mathrm{H} 10 \cdots \mathrm{O} 1 \mathrm{G}$ & $2-x, 2-y, 1-z$ & 3.501(3) & 2.59 & 161.0 \\
\hline $\mathrm{C} 13-\mathrm{H} 13 \cdots \mathrm{Cg} 5^{\mathrm{d}}$ & $1 / 2+x, 5 / 2-y, 1 / 2+z$ & $3.648(2)$ & 2.81 & 147.6 \\
\hline $\mathrm{O} 1 \mathrm{G}-\mathrm{H} 1 \mathrm{G} \cdots \mathrm{O} 1$ & $x, y, 1+z$ & $2.777(2)$ & 2.11 & 136.3 \\
\hline $\mathrm{C} 1 \mathrm{G}-\mathrm{H} 1 \mathrm{G} 1 \cdots \mathrm{S} 1 \mathrm{~B}$ & $x,-1+y, 1+z$ & $3.582(8)$ & 2.84 & 132.7 \\
\hline \multicolumn{5}{|l|}{$3 \mathbf{b}$} \\
\hline $\mathrm{C} 12-\mathrm{H} 12 \cdots \mathrm{O} 1$ & $x,-1+y, z$ & $3.420(3)$ & 2.57 & 149.4 \\
\hline $\mathrm{C} 5-\mathrm{H} 5 \cdots \mathrm{Cg} 2^{\mathrm{k}}$ & $5 / 2-x, 1 / 2+y, 1 / 2-z$ & $3.683(2)$ & 2.89 & 142.3 \\
\hline $\mathrm{C} 6-\mathrm{H} 6 \cdots \mathrm{Cg} 4^{\mathrm{f}}$ & $5 / 2-x, 1 / 2+y, 1 / 2-z$ & $3.624(2)$ & 2.77 & 150.5 \\
\hline $\mathrm{C} 7-\mathrm{H} 7 \cdots \mathrm{Cg} 5^{1}$ & $5 / 2-x, 1 / 2+y, 1 / 2-z$ & $3.704(3)$ & 2.77 & 168.3 \\
\hline \multicolumn{5}{|l|}{ 3c } \\
\hline $\mathrm{C} 4-\mathrm{H} 4 \cdots \mathrm{O} 1$ & $x, 1+y, z$ & $3.334(5)$ & 2.44 & 157.5 \\
\hline $\mathrm{C} 13-\mathrm{H} 13 \cdots \mathrm{Cg} 1^{\mathrm{a}}$ & $3 / 2-x,-1 / 2+y, 1 / 2-z$ & $3.682(4)$ & 2.88 & 143.3 \\
\hline $\mathrm{C} 14-\mathrm{H} 14 \cdots \mathrm{Cg} 3^{\mathrm{b}}$ & $3 / 2-x,-1 / 2+y, 1 / 2-z$ & $3.622(4)$ & 2.75 & 152.5 \\
\hline $\mathrm{C} 15-\mathrm{H} 15 \cdots \mathrm{Cg} 5^{\mathrm{c}}$ & $3 / 2-x,-1 / 2+y, 1 / 2-z$ & $3.672(4)$ & 2.73 & 172.5 \\
\hline \multicolumn{5}{|l|}{ 3d } \\
\hline $\mathrm{C} 4-\mathrm{H} 4 \cdots \mathrm{O} 1$ & $x, 1+y, z$ & $3.374(2)$ & 2.47 & 157.9 \\
\hline $\mathrm{C} 13-\mathrm{H} 13 \cdots \mathrm{Cg} 1^{\mathrm{a}}$ & $3 / 2-x,-1 / 2+y, 1 / 2-z$ & $3.686(2)$ & 2.86 & 145.5 \\
\hline $\mathrm{C} 14-\mathrm{H} 14 \cdots \mathrm{Cg}^{\mathrm{b}}$ & $3 / 2-x,-1 / 2+y, 1 / 2-z$ & $3.657(2)$ & 2.80 & 150.4 \\
\hline $\mathrm{C} 15-\mathrm{H} 15 \cdots \mathrm{Cg} 5^{\mathrm{c}}$ & $3 / 2-x,-1 / 2+y, 1 / 2-z$ & $3.629(2)$ & 2.69 & 169.1 \\
\hline \multicolumn{5}{|l|}{$3 \mathbf{e}$} \\
\hline $\mathrm{O} 1-\mathrm{H} 1 \cdots \mathrm{O} 1 \mathrm{G}$ & $x, y, z$ & $2.681(2)$ & 1.85 & 170.2 \\
\hline $\mathrm{O} 2-\mathrm{H} 2 \mathrm{~A} \cdots \mathrm{O} 1 \mathrm{H}$ & $x, y, z$ & $2.713(2)$ & 1.88 & 168.4 \\
\hline $\mathrm{C} 7-\mathrm{H} 7 \cdots \mathrm{O} 1 \mathrm{H}$ & $x, 1 / 2-y, 1 / 2+z$ & $3.274(3)$ & 2.54 & 134.2 \\
\hline $\mathrm{C} 12-\mathrm{H} 12 \cdots \mathrm{O} 1$ & $-x, 1 / 2+y, 1 / 2-z$ & $3.350(3)$ & 2.57 & 139.5 \\
\hline $\mathrm{C} 13-\mathrm{H} 13 \cdots \mathrm{O} 1 \mathrm{G}$ & $-x, 1 / 2+y, 1 / 2-z$ & $3.343(3)$ & 2.44 & 159.4 \\
\hline $\mathrm{C} 27-\mathrm{H} 27 \cdots \mathrm{O} 1 \mathrm{G}$ & $x, 3 / 2-y,-1 / 2+z$ & 3.382(3) & 2.44 & 174.0 \\
\hline $\mathrm{C} 32-\mathrm{H} 32 \cdots \mathrm{O} 2$ & $1-x, 1 / 2+y, 1 / 2-z$ & 3.352(3) & 2.51 & 147.6 \\
\hline $\mathrm{C} 3 \mathrm{G}-\mathrm{H} 3 \mathrm{G} 2 \cdots \mathrm{O} 1 \mathrm{G}$ & $1-x, 1-y, 1-z$ & $3.582(4)$ & 2.70 & 149.7 \\
\hline $\mathrm{C} 3 \mathrm{H}-\mathrm{H} 3 \mathrm{H} 3 \cdots \mathrm{O} 1 \mathrm{H}$ & $-x, 1-y,-z$ & $3.485(3)$ & 2.66 & 141.8 \\
\hline $\mathrm{C} 4-\mathrm{H} 4 \cdots \mathrm{Cg}^{\mathrm{e}}$ & $1-x,-1 / 2+y, 1 / 2-z$ & $3.433(2)$ & 2.60 & 146.5 \\
\hline $\mathrm{C} 15-\mathrm{H} 15 \cdots \mathrm{Cg} 1^{\mathrm{a}}$ & $-x, 1 / 2+y, 1 / 2-z$ & $3.617(2)$ & 2.91 & 132.6 \\
\hline $\mathrm{C} 24-\mathrm{H} 24 \cdots \mathrm{Cg} 4^{\mathrm{f}}$ & $-x, 1 / 2+y, 1 / 2-z$ & $3.437(2)$ & 2.55 & 155.2 \\
\hline $\mathrm{C} 2 \mathrm{G}-\mathrm{H} 2 \mathrm{G} 2 \cdots \mathrm{Cg} 1^{\mathrm{a}}$ & $1-x, 1-y, 1-z$ & $3.320(3)$ & 2.78 & 115.3 \\
\hline $\mathrm{C} 3 \mathrm{G}-\mathrm{H} 3 \mathrm{G} 3 \cdots \mathrm{Cg} 6^{\mathrm{g}}$ & $x, y, z$ & $3.411(4)$ & 2.60 & 140.2 \\
\hline $\mathrm{C} 3 \mathrm{H}-\mathrm{H} 3 \mathrm{H} 2 \cdots \mathrm{Cg} 5^{\mathrm{h}}$ & $x, y, z$ & 3.536(3) & 2.76 & 136.2 \\
\hline
\end{tabular}


Table 5. Continued

\begin{tabular}{lllll}
\hline \multirow{2}{*}{ Atoms involved } & Symmetry & & Distance $(\AA)$ & Angle (deg) \\
3f & & $\mathrm{D} \cdots \mathrm{A}$ & $\mathrm{H} \cdots \mathrm{A}$ & $\mathrm{A}$ \\
$\mathrm{C} 4-\mathrm{H} 4 \cdots \mathrm{O} 1$ & $1+x, y, z$ & $3.504(2)$ & 2.68 & 145.5 \\
$\mathrm{C} 14-\mathrm{H} 14 \cdots \mathrm{S} 1$ & $x, y, 1+z$ & $3.667(2)$ & 2.96 & 132.2 \\
$\mathrm{C} 5-\mathrm{H} 5 \cdots \mathrm{Cg} 5^{\mathrm{i}}$ & $1+x, y,-1+z$ & $3.666(2)$ & 2.89 & 140.1 \\
$\mathrm{C} 4 \mathrm{G}-\mathrm{H} 4 \mathrm{G} 1 \cdots \mathrm{S} 2$ & $x,-1+y, z$ & $3.836(2)$ & 2.93 & 151.9 \\
$\mathrm{C} 2 \mathrm{G}-\mathrm{H} 2 \mathrm{G} 2 \cdots \mathrm{Cg} 4^{\mathrm{f}}$ & $-x, 1-y, 1-z$ & $3.738(2)$ & 2.86 & 148.8 \\
$\mathrm{C} 3 \mathrm{G}-\mathrm{H} 3 \mathrm{G} 2 \cdots \mathrm{Cg} 2^{\mathrm{k}}$ & $1-x, 1-y, 1-z$ & $3.730(2)$ & 2.95 & 136.5 \\
$\mathrm{C} 4 \mathrm{G}-\mathrm{H} 4 \mathrm{G} 2 \cdots \mathrm{Cg} 4^{\mathrm{f}}$ & $1-x, 1-y, 1-z$ & $3.916(2)$ & 2.97 & 159.5 \\
\hline
\end{tabular}

${ }^{\mathrm{a}} \mathrm{Cg} 1$ is defined as geometric center of the aromatic ring C3-C8.

${ }^{\mathrm{b}} \mathrm{Cg} 3$ is defined as geometric center of the thiophene ring C1-C3, C8 und S1.

${ }^{\mathrm{c}} \mathrm{Cg} 5$ is defined as geometric center of the $\pi$-bond C11-C12.

${ }^{\mathrm{d}} \mathrm{Cg} 5$ is defined as geometric center of the $\pi$-bond C4-C5.

${ }^{\mathrm{e}} \mathrm{Cg} 8$ is defined as geometric center of the thiophene ring C29-C31, C36 und S4.

${ }^{\mathrm{f}} \mathrm{Cg} 4$ is defined as geometric center of the thiophene ring C9-C11, C16 und S2.

${ }^{\mathrm{g}} \mathrm{Cg6}$ is defined as geometric center of the aromatic ring C31-C36.

${ }^{\mathrm{h}} \mathrm{Cg} 5$ is defined as geometric center of the aromatic ring C23-C28.

${ }^{\mathrm{i}} \mathrm{Cg} 5$ is defined as geometric center of the $\pi$-bond C13-C14.

${ }^{\mathrm{k}} \mathrm{Cg} 2$ is defined as geometric center of the aromatic ring C11-C16.

${ }^{1} \mathrm{Cg} 5$ is defined as geometric center of the $\pi$-bond C3-C4. 
Table 6. Non-covalent Interactions in the Crystal Structures Involving 4

\begin{tabular}{|c|c|c|c|c|}
\hline \multirow{2}{*}{ atoms involved } & \multirow{2}{*}{ symmetry } & \multicolumn{2}{|c|}{ distance $(\AA)$} & \multirow{2}{*}{$\begin{array}{l}\text { angle (deg) } \\
\text { D-H } \cdots \text { A }\end{array}$} \\
\hline & & $\mathrm{D} \cdots \mathrm{A}$ & $\mathrm{H} \cdots \mathrm{A}$ & \\
\hline \multicolumn{5}{|l|}{4} \\
\hline $\mathrm{C} 30-\mathrm{H} 30 \cdots \mathrm{O} 1$ & $x, y, z$ & $3.599(2)$ & 2.70 & 158.6 \\
\hline $\mathrm{C} 2-\mathrm{H} 2 \mathrm{~A} \cdots \mathrm{S} 2$ & $x, y, z$ & 3.393(2) & 2.83 & 118.9 \\
\hline $\mathrm{C} 22-\mathrm{H} 22 \cdots \mathrm{S} 1$ & $x, y, z$ & $3.607(2)$ & 2.82 & 140.3 \\
\hline $\mathrm{C} 33-\mathrm{H} 33 \cdots \mathrm{S} 3$ & $1-x, 1-y, 1-z$ & $3.741(2)$ & 2.86 & 155.3 \\
\hline $\mathrm{O} 1-\mathrm{H} 1 \cdots \mathrm{Cg} 9^{\mathrm{a}}$ & $x, y, z$ & $3.483(1)$ & 2.66 & 166.5 \\
\hline $\mathrm{O} 2-\mathrm{H} 2 \cdots \mathrm{Cg} 1^{\mathrm{b}}$ & $-1+x, y, z$ & 3.339(1) & 2.70 & 134.6 \\
\hline $\mathrm{C} 5-\mathrm{H} 5{ }^{\cdots} \mathrm{Cg} 2^{\mathrm{c}}$ & $x, y, z$ & $3.577(2)$ & 2.77 & 143.1 \\
\hline \multicolumn{5}{|l|}{$4 \mathbf{a}$} \\
\hline $\mathrm{O} 1-\mathrm{H} 1 \cdots \mathrm{N} 1 \mathrm{G}$ & $x,-1+y, z$ & $2.718(2)$ & 1.89 & 168.1 \\
\hline $\mathrm{C} 5-\mathrm{H} 5 \cdots \mathrm{S} 2 \mathrm{~B}$ & $1 / 2+x, 1 / 2-y, 1 / 2+z$ & $3.667(4)$ & 2.86 & 144.0 \\
\hline N1G-H1G $\cdots \mathrm{O} 1$ & $1-x, 1-y,-z$ & $3.031(2)$ & $2.18(2)$ & $167.1(2)$ \\
\hline $\mathrm{C} 12-\mathrm{H} 12 \cdots \mathrm{Cg} 3^{\mathrm{h}}$ & $-x, 1-y,-z$ & $3.525(2)$ & 2.70 & 146.0 \\
\hline $\mathrm{C} 15-\mathrm{H} 15 \cdots \mathrm{Cg} 5^{\mathrm{i}}$ & $1-x, 1-y,-z$ & $3.787(2)$ & 2.84 & 173.3 \\
\hline $\mathrm{C} 19-\mathrm{H} 19 \cdots \mathrm{Cg} 6^{\mathrm{k}}$ & $-x, 1-y,-z$ & $3.694(2)$ & 2.75 & 170.1 \\
\hline $\mathrm{C} 2 \mathrm{G}-\mathrm{H} 2 \mathrm{G} 3 \mathrm{Cg} 3^{\mathrm{h}}$ & $-x, 1-y,-z$ & $3.652(2)$ & 2.87 & 137.5 \\
\hline \multicolumn{5}{|l|}{$4 b$} \\
\hline $\mathrm{O} 1-\mathrm{H} 1 \cdots \mathrm{N} 1 \mathrm{G}$ & $x, y, z$ & $2.645(2)$ & 1.83 & 164.8 \\
\hline $\mathrm{C} 5-\mathrm{H} 5 \cdots \mathrm{S} 2 \mathrm{~B}$ & $-x, 2-y,-z$ & $3.555(1)$ & 2.84 & 132.4 \\
\hline $\mathrm{C} 12-\mathrm{H} 12 \cdots \mathrm{S} 2 \mathrm{~B}$ & $1-x, 2-y,-z$ & $3.445(1)$ & 2.76 & 129.3 \\
\hline N1G-H1G $\cdots \mathrm{O} 1$ & $1-x, 1-y, 1-z$ & $3.035(2)$ & $2.22(2)$ & $164(2)$ \\
\hline $\mathrm{C} 4 \mathrm{G}-\mathrm{H} 4 \mathrm{G} 2 \cdots \mathrm{S} 2$ & $x, y, z$ & $3.738(2)$ & 2.97 & 135.1 \\
\hline $\mathrm{C} 7-\mathrm{H} 7 \cdots \mathrm{Cg} 2^{\mathrm{C}}$ & $x,-1+y, z$ & $3.579(2)$ & 2.63 & 177.9 \\
\hline $\mathrm{C} 13-\mathrm{H} 13 \cdots \mathrm{Cg} 5^{\mathrm{i}}$ & $1-x, 2-y,-z$ & $3.669(2)$ & 2.81 & 150.6 \\
\hline $\mathrm{C} 2 \mathrm{G}-\mathrm{H} 2 \mathrm{G} 2 \cdots \mathrm{Cg} 1^{\mathrm{b}}$ & $1+x, y, z$ & $3.624(2)$ & 2.78 & 143.1 \\
\hline \multicolumn{5}{|l|}{$4 c$} \\
\hline $\mathrm{O} 1-\mathrm{H} 1 \cdots \mathrm{O} 1 \mathrm{G}$ & $1-x, 1-y, 1-z$ & $2.775(3)$ & 1.95 & 167.4 \\
\hline $\mathrm{C} 7-\mathrm{H} 7 \cdots \mathrm{O} 1$ & $-x,-y,-z$ & $3.460(5)$ & 2.63 & 146.4 \\
\hline $\mathrm{C} 19-\mathrm{H} 19 \cdots \mathrm{S} 1 \mathrm{~B}$ & $x, y, z$ & $3.332(5)$ & 2.93 & 107.0 \\
\hline $\mathrm{C} 2 \mathrm{G}-\mathrm{H} 2 \mathrm{G} 1 \cdots \mathrm{S} 2$ & $x, y, 1+z$ & $3.200(4)$ & 2.75 & 108.8 \\
\hline $\mathrm{C} 2 \mathrm{G}-\mathrm{H} 2 \mathrm{G} 2 \cdots \mathrm{S} 1$ & $1-x,-y, 1-z$ & $3.680(4)$ & 2.86 & 142.1 \\
\hline $\mathrm{C} 2-\mathrm{H} 2 \cdots \mathrm{Cg} 6^{\mathrm{d}}$ & $1-x,-1 / 2+y, 1 / 2-z$ & $3.725(1)$ & 2.88 & 148.9 \\
\hline $\mathrm{C} 13-\mathrm{H} 13 \cdots \mathrm{Cg} 4^{\mathrm{e}}$ & $1-x, 1 / 2+y, 1 / 2-z$ & $3.579(3)$ & 2.93 & 126.7 \\
\hline \multicolumn{5}{|l|}{$4 d$} \\
\hline $\mathrm{O} 1-\mathrm{H} 1 \cdots \mathrm{O} 1 \mathrm{G}$ & $x, y,-1+z$ & $2.724(2)$ & 1.91 & 163.8 \\
\hline $\mathrm{C} 13-\mathrm{H} 13 \cdots \mathrm{S} 1$ & $1-x, 1 / 2+y, 1 / 2-z$ & $3.829(2)$ & 2.96 & 152.2 \\
\hline $\mathrm{C} 19-\mathrm{H} 19 \cdots \mathrm{S} 2$ & $1-x, 1-y,-z$ & $3.576(2)$ & 2.86 & 133.1 \\
\hline $\mathrm{C} 2-\mathrm{H} 2 \cdots \mathrm{Cg} 6^{\mathrm{f}}$ & $x, 1+y,-1+z$ & $3.557(2)$ & 2.79 & 138.3 \\
\hline $\mathrm{C} 5-\mathrm{H} 5 \cdots \mathrm{Cg} 5^{\mathrm{g}}$ & $1+x, 1+y, z$ & $3.661(2)$ & 2.92 & 135.2 \\
\hline $\mathrm{C} 12-\mathrm{H} 12 \cdots \mathrm{Cg}^{\mathrm{e}}$ & $1-x, 1 / 2+y, 1 / 2-z$ & $3.531(2)$ & 2.73 & 143.0 \\
\hline
\end{tabular}


Table 6. Continued

\begin{tabular}{|c|c|c|c|c|}
\hline \multirow{2}{*}{ atoms involved } & \multirow{2}{*}{ symmetry } & \multicolumn{2}{|c|}{ distance $(\AA)$} & \multirow{2}{*}{$\begin{array}{l}\text { angle (deg) } \\
\text { D-H } \cdots \text { A }\end{array}$} \\
\hline & & $\mathrm{D} \cdots \mathrm{A}$ & $\mathrm{H} \cdots \mathrm{A}$ & \\
\hline \multicolumn{5}{|l|}{$4 e$} \\
\hline $\mathrm{O} 1-\mathrm{H} 1 \cdots \mathrm{O} 1 \mathrm{G}$ & $x,-1+y,-1+z$ & $2.726(3)$ & 1.91 & 162.4 \\
\hline $\mathrm{O} 1-\mathrm{H} 1 \cdots \mathrm{O} 2 \mathrm{~GB}$ & $x,-1+y,-1+z$ & $2.783(5)$ & 2.24 & 122.5 \\
\hline $\mathrm{C} 4-\mathrm{H} 4 \cdots \mathrm{O} 2 \mathrm{G}$ & $1-x, 1-y, 1-z$ & $3.493(4)$ & 2.70 & 141.6 \\
\hline $\mathrm{C} 5-\mathrm{H} 5 \cdots \mathrm{S} 2$ & $1-x, 1 / 2+y, 1 / 2-z$ & $3.429(3)$ & 2.99 & 109.7 \\
\hline $\mathrm{C} 1 \mathrm{G}-\mathrm{H} 1 \mathrm{G} 1 \cdots \mathrm{O} 1 \mathrm{G}$ & $1-x, 2-y, 2-z$ & $3.223(2)$ & 2.61 & 120.3 \\
\hline $\mathrm{C} 7-\mathrm{H} 7 \cdots \mathrm{C} 15_{\mathrm{Ar}}$ & $x, 1+y, z$ & $3.689(3)$ & 2.84 & 149.9 \\
\hline $\mathrm{C} 13-\mathrm{H} 13 \cdots \mathrm{Cg} 6^{1}$ & $-x,-1 / 2+y, 1 / 2-z$ & $3.758(2)$ & 2.83 & 166.8 \\
\hline $\mathrm{C} 1 \mathrm{G}-\mathrm{H} 1 \mathrm{G} 2 \cdots \mathrm{Cg} 5^{\mathrm{m}}$ & $1-x, 2-y, 1-z$ & $3.594(1)$ & 2.65 & 159.1 \\
\hline $\mathrm{C} 4 \mathrm{G}-\mathrm{H} 4 \mathrm{G} 1 \cdots \mathrm{Cg} 4^{\mathrm{e}}$ & $x, 1+y, 1+z$ & $3.722(7)$ & 2.98 & 132.8 \\
\hline C4GB-H4G4 $\cdots \mathrm{Cg}^{\mathrm{h}}{ }^{\mathrm{h}}$ & $x, y, 1+z$ & $3.598(2)$ & 2.63 & 164.6 \\
\hline
\end{tabular}

${ }^{a}$ Cg9 is defined as geometric center of the $\pi$-bond C23-C24.

${ }^{\mathrm{b}} \mathrm{Cg} 1$ is defined as geometric center of the aromatic ring C3-C8.

${ }^{\mathrm{c}} \mathrm{Cg} 2$ is defined as geometric center of the aromatic ring C11-C16.

${ }^{\mathrm{d}} \mathrm{Cg} 6$ is defined as geometric center of the $\pi$-bond C14-C15.

${ }^{\mathrm{e}} \mathrm{Cg} 4$ is defined as geometric center of the thiophene ring C9-C11, C16 und S2.

${ }^{\mathrm{f}} \mathrm{Cg} 6$ is defined as geometric center of the $\pi$-bond C1G-O1G.

${ }^{\mathrm{g}} \mathrm{Cg} 5$ is defined as geometric center of the $\pi$-bond C14-C15.

${ }^{\mathrm{h}} \mathrm{Cg} 3$ is defined as geometric center of the thiophene ring C1-C3, C8 und S1.

${ }^{\mathrm{i}} \mathrm{Cg} 5$ is defined as geometric center of the $\pi$-bond C7-C8.

${ }^{\mathrm{k}}$ Cg6 is defined as geometric center of the $\pi$-bond C12-C13.

${ }^{\mathrm{l}} \mathrm{Cg} 6$ is defined as geometric center of the $\pi$-bond C15-C16.

${ }^{\mathrm{m}} \mathrm{Cg} 5$ is defined as geometric center of the $\pi$-bond C5-C6. 